\title{
Fluorescent biological aerosol particle measurements at a tropical high-altitude site in southern India during the southwest monsoon season
}

\author{
A. E. Valsan ${ }^{1}$, R. Ravikrishna ${ }^{2}$, C. V. Biju ${ }^{3}$, C. Pöhlker ${ }^{4}$, V. R. Després ${ }^{5}$, J. A. Huffman ${ }^{6}$, U. Pöschl ${ }^{7}$, and S. S. Gunthe \\ ${ }^{1}$ EWRE Division, Department of Civil Engineering, Indian Institute of Technology Madras, \\ Chennai, 600 036, India \\ ${ }^{2}$ Department of Chemical Engineering, Indian Institute of Technology Madras, \\ Chennai, 600 036, India \\ ${ }^{3}$ Department of Civil Engineering, College of Engineering Munnar, PB.No:45, County Hills, \\ Munnar, 685612, India \\ ${ }^{4}$ Biogeochemistry Department, Max Planck Institute for Chemistry, P.O. Box 3060, \\ Mainz, Germany \\ ${ }^{5}$ Institute of General Botany, Johannes Gutenberg University, \\ Mainz, Germany \\ ${ }^{6}$ Department of Chemistry and Biochemistry, University of Denver, 2190 E. Iliff Ave., \\ Denver, CO, 80208, USA \\ ${ }^{7}$ Multiphase Chemistry Department, Max Planck Institute for Chemistry, P.O. Box 3060, \\ Mainz, Germany
}

Correspondence to: A. E. Valsan (aswathyerat@gmail.com) and S. S. Gunthe (s.gunthe@iitm.ac.in)

Received: 26 March 2016 - Published in Atmos. Chem. Phys. Discuss.: 8 April 2016

Revised: 5 July 2016 - Accepted: 14 July 2016 - Published: 4 August 2016

\begin{abstract}
An ultraviolet aerodynamic particle sizer (UVAPS) was continuously operated for the first time during two seasons to sample the contrasting winds during monsoon and winter to characterize the properties of fluorescent biological aerosol particles (FBAPs), at a high-altitude site in India. Averaged over the entire monsoon campaign (1 June21 August 2014), the arithmetic mean number and mass concentrations of coarse-mode $(>1 \mu \mathrm{m})$ FBAPs were $0.02 \mathrm{~cm}^{-3}$ and $0.24 \mu \mathrm{g} \mathrm{m}^{-3}$, respectively, which corresponded to $\sim 2$ and $6 \%$ of total aerosol loading, respectively. Average FBAP number size distribution exhibited a peak at $\sim 3 \mu \mathrm{m}$, which is attributed to the fungal spores, as supported by scanning electron microscope (SEM) images, and these results are consistent with previous studies made for FBAPs. During 11 weeks of measurements the variability of the total coarse-mode particle number (TAP) concentration was high compared to that observed in FBAP number concentrations. The TAP and FBAP number concentrations measured at this site were strongly dependent on changes in wind direction
\end{abstract}

and rainfall. During periods of westerly/southwesterly winds with heavy persistent rainfall, the TAP and FBAP concentrations exhibited very low values $\left(1.3\right.$ and $0.005 \mathrm{~cm}^{-3}$, respectively) with no significant diurnal variations, whereas during periods of northerly winds with scattered rainfall FBAPs exhibited relatively high concentration values $\left(0.05 \mathrm{~cm}^{-3}\right)$ with pronounced diurnal variations, which were strongly coupled with diurnal variations in meteorological parameters. The campaign-averaged FBAP number concentrations were shown to correlate with daily patterns of meteorological parameters and were positively correlated with relative humidity $\left(\mathrm{RH} ; R^{2}=0.58\right)$ and negatively with temperature $\left(R^{2}=0.60\right)$ and wind speed $\left(R^{2}=0.60\right)$. We did not observe any significant positive correlation with precipitation as reported by previous researchers from selected areas. These measurement results confirm the fact that the ratio of PBAPs to TAP is strongly dependent on particle size and location and thus may constitute a significant proportion of total aerosol particles. 


\section{Introduction}

Aerosols are generally defined as a colloidal system of solid or liquid particles suspended in a gaseous medium (Fuzzi et al., 1997; Pöschl, 2005) and are ubiquitous in the Earth's atmosphere. The term "primary biological aerosol particles" (PBAPs; sometimes also referred to as bioaerosols or biological aerosols) describes a subset of solid airborne particles originating from biological organisms, including viruses, pollen, microorganisms (bacteria, fungal spores, etc.) and protozoa or algae, together with fragments of biological materials such as animal dander and plant debris (Artaxo and Hansson, 1995; Coz et al., 2010; Després et al., 2007, 2012; Elbert et al., 2007). Bioaerosols can range in size from a few nanometers to a few hundred micrometers in aerodynamic diameter, $D_{\mathrm{a}}$ (Coz et al., 2010; Després et al., 2012; Jones and Harrison, 2004; Matthias-Maser and Jaenicke, 1994). PBAPs have been shown to constitute $14-70 \%$ of the total number of coarse-mode particles and around $20-24 \%$ of the total mass of $\mathrm{PM}_{10}$ (particulate matter with size $\leq 10 \mu \mathrm{m}$; Elbert et al., 2007; Després et al., 2012; Pöschl et al., 2010; Huffman et al., 2012). Furthermore, it is likely that the surface structure, ice nucleating proteins, and other characteristics of bioaerosols can influence the heterogeneous ice nuclei (IN) formation at relatively high temperature levels (Morris et al., 2004, 2014). Bioaerosols can thus act as giant cloud condensation nuclei (GCCN), thus affecting the hydrological cycle (Andreae and Rosenfeld, 2008; Möhler et al., 2007). It is also known that pollen and spores associated with various plants and fungi are dispersed in air, resulting in the distribution and transfer of genetic material over large distances (Huffman et al., 2010; Elbert et al., 2007; Hallar et al., 2011; Burrows et al., 2009). A side-effect of such transport and distribution is that they can play a negative role in public health. Pathogenic fungi have long been recognized as major threats to animal health and plants including crops, severely jeopardizing food security (Fisher et al., 2012, and references therein).

The last decade has experienced substantial development and application of advanced online and offline techniques for studying the characteristic properties of bioaerosols in both the field and laboratory (Fröhlich-Nowoisky, et al., 2009; DeLeon-Rodriguez et al., 2013; Prenni et al., 2009; Huffman et al., 2010, 2012, 2013; Schumacher et al., 2013; Pöhlker et al., 2012, 2013). Instruments utilizing laser-induced fluorescence (LIF) have been frequently deployed in the field, enabling real-time characterization of the number size distribution of primary biological aerosol particles (PBAPs) with high time and size resolution. However, instruments based on LIF do not provide detailed information directly about PBAPs or the origin of particles, but provide broadly categorized information due to a mixture of biological fluorophores, each detected with varying efficiency (Pöhlker et al., 2012, 2013). Most fluorescent biological aerosol particle (FBAP) measurements have shown that the dominant size range for PBAP number size distribution is $1-4 \mu \mathrm{m}$, with concentra- tion varying within a factor of 10 (Gabey et al., 2011, 2013; Healy et al., 2014; Huffman et al., 2010, 2012, 2013; Saari et al., 2015; Schumacher et al., 2013; Toprak and Schnaiter, 2013; Yu et al., 2016). As studied and described by Huffman et al. (2010), based on 4 months of measurements in central Europe, the signal detected by a UV-APS (ultraviolet aerodynamic particle sizer) was defined as FBAPs. Hence, the term "FBAP" is used as a lower limit proxy for PBAPs, biological aerosols, biological aerosol particles, bioaerosols and similar terms mentioned in this study.

Despite such instrumental advancements as described above, studies related to the quantification of bioaerosols and their role in climate and human health have been extremely limited in space and time. This is particularly true for the Indian subcontinent, which contains $\sim 18 \%$ of the world's total population, where studies related to the bioaerosols are relatively few and with analysis performed only by traditional techniques (Bhati and Gaur, 1979; Chakraborty et al., 1998; Gangamma, 2014; Srivastava et al., 2012; Sharma and Rai, 2008; Pachauri et al., 2013; Valsan et al., 2015; Ansari et al., 2015; Adhikari et al., 2004). The abundance of bioaerosols, which are strongly dependent on location and season, remains poorly characterized over the Indian subcontinent and needs to be addressed systematically.

Additionally, investigating and quantifying the role of bioaerosols over the Indian sub-continent is important due to its diverse land-use pattern and the unique climatic condition experienced in terms of two monsoon seasons associated with two distinct synoptic-scale wind patterns. The concentration of fluorescent aerosol particles in a semi-arid forest in the western USA was shown to increase during and after rainfall (Huffman et al., 2013). Rainfall-triggered increase in bioaerosol concentration can potentially enhance further precipitation by convective upward movement of bioaerosols into clouds where they can serve either as IN or GCCN (Schumacher et al., 2013; Huffman et al., 2013). Thus, the bioaerosols emitted during monsoon rainfall could potentially play an important role in cloud and precipitation formation over India (Ansari et al., 2015).

Therefore, it is very important to understand and quantify the role of bioaerosols in cloud and precipitation formation during monsoon and convective rainfall. Additionally, bioaerosols over the Indian sub-continent can directly impact society through the spread of diseases and indirectly due to increased risk of loss of agricultural output due to emerging diseases caused by the fungi (Fisher et al., 2012).

Studies involving characterization of bioaerosols using advanced techniques over this region are important to understand and quantify the impact of bioaerosols on regional biodiversity with larger implication for human and ecosystem health. With this motivation we have deployed a UV-APS for the detection and measurement of number size distribution of PBAPs at a high-altitude site of Munnar in the Western Ghats of southern tropical India during the southwest monsoon season for $\sim 3$ months. To our knowledge this study presents the 
first ambient measurement investigation involving UV-APS for multiple months over the Indian subcontinent.

\section{Methods}

\subsection{Site description}

Measurements were performed to sample the air masses (see Sect. 2.2) from a high-altitude site (Munnar; $10.09^{\circ} \mathrm{N}$, $77.06^{\circ} \mathrm{E} ; 1605 \mathrm{~m}$ a.m.s.l. - above mean sea level - Fig. 1) located in the Western Ghats region of southern, tropical India, just $90 \mathrm{~km}$ away from the Arabian Sea. The observational site is located on a hill with a valley towards the south and a small mountain towards the north surrounded by dense vegetation including tea gardens and eucalyptus trees. Climatologically this region is classified as subtropical highland with dry winters and is listed as the Shola forest-grass ecosystem as defined in the land-use type terminology (Fig. S1 in the Supplement). The Western Ghats, one of the eight mountain ranges in India and identified as one of the most significant hotspots of biodiversity (Myers et al., 2000) in the world, originates near the border of Maharashtra and Gujarat, running $\sim 1600 \mathrm{~km}$ towards the south, parallel to the western coast through the states of Gujarat, Maharashtra, Karnataka, Kerala, and Tamilnadu, ending at the southern tip of India near Kanyakumari. This mountain range separates the coastal plain from the Deccan plateau, making the western coastal plain a narrow land strip with a maximum width of $\sim 110-120 \mathrm{~km}$ sandwiched between the Western Ghats and the Arabian Sea. During the southwest monsoon season (June-September) the southwesterly, moisture laden winds are intercepted by the Western Ghats, causing persistent and heavy rainfall on the windward side of these mountains. This causes the washout and wet deposition of the pollutants in the coastal strip (Kerala) emitted due to anthropogenic activities, thus bringing clean marine influx with minimum impact of anthropogenic emissions (Satheesh and Srinivasan, 2002). Therefore, during this particular season this observational site can be regarded as relatively pristine, as compared to any other operational high-altitude observatory/site in the Indian tropical region (Shika et al., 2016).

\subsection{General meteorology}

Southern India nominally experiences two monsoon seasons, the southwest (SW) monsoon and the northeast monsoon (NE; November-January), which are strongly associated with the movement of the Inter-Tropical Convergence Zone, the ITCZ (Kanawade et al., 2014). The SW monsoon winds bring relatively clean marine influx over the continent from the Arabian Sea when the ITCZ moves northwards, reaching $30^{\circ} \mathrm{N}$ during July (Naja and Lal, 2002). These air masses originate over the Indian Ocean and travel thousands of kilometers over the ocean, including the Arabian Sea, before reaching the observational site. The southward move- ment of ITCZ reaching up to the Equator is associated with the NE monsoon, which is also marked as the winter season in India occurring from October to January, when the prevailing winds predominantly blow in the northeasterly direction. The measurement site of Munnar receives more than $85 \%$ of its annual rainfall during the SW monsoon season and experiences scattered rainfall events during the NE monsoon. The detailed meteorological parameters measured during the field measurement campaign carried out during the SW monsoon season at Munnar are discussed below.

\subsection{Real-time fluorescence measurement}

Biological aerosol particles at Munnar were measured using a UV-APS (TSI Inc. model 3314) as per the standard instructions given in the technical manual. The detailed description of the instrument, including operating principles, field operation, data analysis protocol, and critical operational parameters, is given elsewhere (Kanaani et al., 2007, 2008; Agranovski et al., 2003, 2004, 2005; Brosseau et al., 2000; Huffman et al., 2010, 2012; Hairston et al., 1997).

Briefly, the instrument is capable of measuring aerosol particles in the aerodynamic diameter $\left(D_{\mathrm{a}}\right)$ range of $0.5-20 \mu \mathrm{m}$ over 52 channels by measuring the time-of-flight of particles between two He-Ne red lasers $(\lambda=633 \mathrm{~nm})$. Once the particle size is determined, each particle is excited using an ultraviolet Nd:YAG laser $(\lambda=355 \mathrm{~nm})$ and fluorescent emission is measured in the range of $420-575 \mathrm{~nm}$. The spectrally unresolved total fluorescence is recorded for each individual particle in 1 of 64 channels. The UV-APS measurements were obtained at $5 \mathrm{~min}$ intervals (recording a total of $22280 \mathrm{sam}-$ pling points during the entire measurement campaign) with a volumetric flow rate of $5 \mathrm{~L} \mathrm{~min}^{-1}$ at ambient temperature and pressure. All times reported in this study were Indian Standard Time (IST).

Sampling was performed at a building of the College of Engineering, Munnar, Kerala. The sampling inlet was approximately $2 \mathrm{~m}$ above the rooftop of the building and $8 \mathrm{~m}$ above the ground level. The sampling inlet was connected to the UV-APS, which was placed next to the window inside a room using $3 \mathrm{~m}$ of $6.35 \mathrm{~mm}$ OD stainless steel tubing. To minimize the particle losses due to impaction resulting from sharp bends, electrically conductive silicon rubber tubing ( $\sim 1.5 \mathrm{~m} ; 12 \mathrm{~mm}$ inner diameter) was attached to the stainless steel tube just outside the window (Fig. S1). The air sample was passed through a diffusion dryer ( $\sim 1$ m length) with silica gel before entering the UV-APS, thus maintaining the relative humidity of inlet air to $<40 \%$. The residence time of sampled air in the inlet tube was calculated to be $\sim 20 \mathrm{~s}$, and the flow was calculated to be laminar in the entire sampling line. Hence, diffusion losses were expected to be negligible for all the size ranges of the sampled particles (average penetration efficiency of $99.8 \%$ at $290 \mathrm{~K}$ and $840 \mathrm{hPa}$; Baron and Willeke, 2005). 

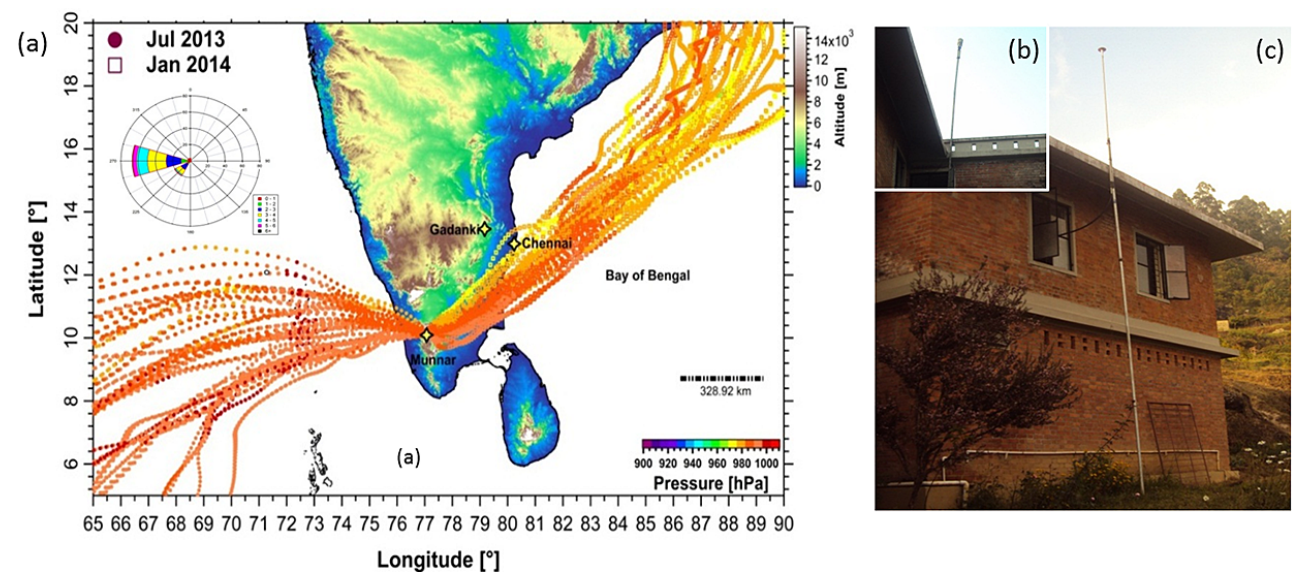

Figure 1. Location of measurement site Munnar $\left(10.09^{\circ} \mathrm{N}, 77.06^{\circ} \mathrm{E} ; 1605 \mathrm{~m}\right.$ a.m.s.1. - above mean sea level) located in the Western Ghats mountain range in southern tropical India with 10-day back-trajectories (HYSPLIT, NOAA-ARL GDAS1 model; start height $50 \mathrm{~m}$ above ground level; start time 23:30 LT, local time) illustrating the distinct and contrasting wind patterns during two contrasting seasons: southwest monsoon season (representative month July) and winter season (representative month January) when field measurement campaigns were carried out. It is evident that the predominant wind pattern during the southwest monsoon season was westerly/southwesterly, bringing the clean marine influx as also evident from the wind rose diagram shown in inset (a). The meteorological parameters were recorded using the weather station installed close to the inlet system (b). The inlet system prepared for sampling the air using an ultraviolet aerodynamic particle sizer (UV-APS) for bioaerosol number size distribution measurement (c). The map shown is color-coded by topography (meters) and trajectories are color-coded by atmospheric pressure level (hPa).

Table 1. List of frequently used acronyms and symbols with units.

\begin{tabular}{|c|c|}
\hline Symbol & Quantity, unit \\
\hline$D_{\mathrm{a}}$ & Aerodynamic diameter, $\mu \mathrm{m}$ \\
\hline$D_{\mathrm{g}}$ & Geometric midpoint diameter of fluorescent particles \\
\hline$D_{\mathrm{g}, \mathrm{T}}$ & Geometric midpoint diameter of total particles \\
\hline DNA & Deoxyribonucleic acid \\
\hline FBAP & Fluorescent biological aerosol particle \\
\hline $\mathrm{He}-\mathrm{Ne}$ & Helium-neon \\
\hline ITCZ & Inter-Tropical Convergence Zone \\
\hline $\mathrm{L} \min ^{-1} M_{\mathrm{F}}$ & Liters per minute integrated mass concentration of fluorescent particles, $\mu \mathrm{g} \mathrm{m}^{-3}$ \\
\hline$M_{\mathrm{T}}$ & Integrated mass concentration of total particles, $\mu \mathrm{g} \mathrm{m}^{-3}$ \\
\hline Nd:YAG & Neodymium-doped yttrium aluminum garnet \\
\hline $\mathrm{NE}$ & Northeast \\
\hline$N_{\mathrm{F}}$ & Integrated number concentration of fluorescent particles, $\mathrm{cm}^{-3}$ \\
\hline$N_{\mathrm{T}}$ & Integrated number concentration of total particles, $\mathrm{cm}^{-3}$ \\
\hline PAH & Polycyclic aromatic hydrocarbon \\
\hline PBAPs & Primary biological aerosol particles \\
\hline RH & Relative humidity \\
\hline SEM & Scanning electron microscopy \\
\hline SW & Southwest \\
\hline TAP & Total aerosol particle \\
\hline TSP & Total suspended particle \\
\hline UV-APS & Ultraviolet aerodynamic particle sizer \\
\hline$\lambda$ & Wavelength, nm \\
\hline
\end{tabular}

For the present study the number size distribution of fluorescence biological aerosol particles $\left(\mathrm{d} N_{\mathrm{F}} / \mathrm{d} \log D_{\mathrm{a}}\right)$ for each size bin was derived by summing up the particle number concentration from fluorescence channel numbers 3 to
64, and similarly the total particle number size distribution $\left(\mathrm{d} N_{\mathrm{T}} / \mathrm{d} \log D_{\mathrm{a}}\right)$ was derived from channel numbers 1 to 64 . In the present study we have used $1.0 \mu \mathrm{m}$ as a cutoff diameter for a given $\mathrm{d} N_{\mathrm{F}} / \mathrm{d} \log D_{\mathrm{a}}$ and $\mathrm{d} N_{\mathrm{T}} / \mathrm{d} \log D_{\mathrm{a}}$ to cal- 
culate the fluorescence biological aerosol number and total aerosol number concentrations, $N_{\mathrm{F}}$ and $N_{\mathrm{T}}$, respectively. This is mainly due to the fact that the particle counting efficiency of the UV-APS drops below unity at $0.7 \mu \mathrm{m}$ (counting efficiency $\sim 50 \%$ at $0.54 \mu \mathrm{m}$ ) and the interferences from non-biological aerosol particles below $1.0 \mu \mathrm{m}$ can at times be very high (Huffman et al., 2010). A few other studies have reported a decrease in the UV-APS counting efficiency for FBAPs $<2 \mu \mathrm{m}$ based on comparison of ambient FBAPs with another LIF instrument (WIBS and BioScout) using different fluorescence wavelengths (Healy et al., 2014; Saari et al., 2014). In the present study we define $1 \mu \mathrm{m}$ as the cutoff diameter to distinguish between the sub-micron $(<1 \mu \mathrm{m})$ and super-micron $(>1 \mu \mathrm{m})$ modes of the particle number size distribution. The subscripts " $F$ " and " $T$ " throughout this paper refer to fluorescent and total coarse-mode particles, respectively. See Table 1 for abbreviations, notations, and symbols used in this paper. The particle mass size distributions $\left(\mathrm{d} M / \operatorname{d} \log D_{\mathrm{a}}\right)$ for total as well as fluorescent biological aerosol particles were calculated for each size bin by multiplying $\mathrm{d} N / \operatorname{d} \log D_{\mathrm{a}}$ by the volume of an aerodynamically equivalent sphere with the geometric midpoint diameter $\left(D_{\mathrm{a}, \mathrm{g}}\right)$ and assuming the unit density $\left(1 \mathrm{~g} \mathrm{~cm}^{-3}\right)$ and unit shape factor. The integral mass concentrations of coarse fluorescent biological aerosol particles and total coarse particles, $M_{\mathrm{F}}$ and $M_{\mathrm{T}}$, respectively, were calculated by integrating the particle mass distribution for $D_{\mathrm{a}}>1 \mu \mathrm{m}$; thus, the particle mass reported here should be viewed in a first approximation as a result of uncertainty associated with the density and shape of the particles (Huffman et al., 2010). To be consistent with previous UV-APS results, no standard temperature and pressure (STP) corrections were applied to the concentrations reported in this study. These number concentrations can be normalized to the volume that the sampled air would occupy under dry standard conditions (STP: $273 \mathrm{~K}$, $1000 \mathrm{hPa}$, and $0 \% \mathrm{RH}$ ) by multiplying the concentration values reported here by a factor of 1.29 derived using the ideal gas law.

\section{Fluorescence of sub-micron particles}

It has been reported by previous researchers that UVAPS is known to exhibit fluorescence for some fraction of non-biological aerosol particles including soot, PAHs, and cigarette smoke, which could be erroneously counted as FBAPs (Huffman et al., 2010; Pan et al., 1999a, b). To investigate the contribution of non-biological aerosol particles that are counted as fluorescence biological aerosol particles, Huffman et al. (2010) showed the correlation between the integrated number concentrations of fluorescent particles $\left(N_{\mathrm{F}}\right)$ and total particles $\left(N_{\mathrm{T}}\right)$ for different diameter ranges (only for the fluorescence channels $>3$ ). To examine the influence of anthropogenic emissions on sub-micron fluorescent particles, we performed a similar correlation analysis for the entire campaign. The correlation between integrated number concentrations of fluorescent particles $\left(N_{\mathrm{F}}\right)$ and total particles $\left(N_{\mathrm{T}}\right)$ for the super-micron $\left(D_{\mathrm{a}}>1 \mu \mathrm{m}\right)$ and sub-micron $\left(D_{\mathrm{a}}<1 \mu \mathrm{m}\right)$ diameter ranges exhibited a very poor scatter $\left(R^{2}=0.03\right.$ and $R^{2}=0.002$, respectively; $N=22280$; Fig. S2), indicating an extremely small percentage of fluorescence contributed by non-biological aerosol particles in both the super-micron and sub-micron particle ranges. This was in contrast with the observations in Huffman et al. (2010).

Since a certain component of the mineral dust may exhibit a weak fluorescence (Huffman et al., 2010; Sivaprakasam et al., 2004; Toprak and Schnaiter, 2013), we performed the separate correlation analysis for the dusty period, which was dominated by the transport of mineral dust from western Asia, northern Africa, and the Arabian region (discussed below). The correlation between integrated number concentrations of $N_{\mathrm{F}}$ and $N_{\mathrm{T}}$ for $D_{\mathrm{a}}>1 \mu \mathrm{m}$ was moderately linear $\left(R^{2}=0.26 ; N=3138\right.$; Fig. S3a) compared to the submicron size range during the dusty period $\left(R^{2}=0.007 ; N=\right.$ 3138; Fig. S3b), indicating that the fraction of super-micron particles exhibiting fluorescence may have been contributed by mineral dust, but not for sub-micron particles.

From these analyses we infer that the contribution of non-biological aerosol particles exhibiting fluorescence was negligible in both the sub-micron and super-micron (except during the "dusty period"; discussed below) size ranges. Thus we hypothesize that due to persistent rainfall the sub-micron and super-micron particles resulting from combustion-related activities were either efficiently removed or were not transported to the observation site. Thus this observation site could be termed relatively pristine and free from anthropogenic emissions during the monsoon season, making this site scientifically interesting for investigating the characteristic properties of bioaerosols on a long-term basis using advanced online and offline techniques.

However, to maintain the consistency and uniformity in the comparison of $N_{\mathrm{F}}, N_{\mathrm{T}}$, and other similar parameters reported in previous studies, all the statistics associated with $\mathrm{d} N_{\mathrm{F}} / \operatorname{d} \log D_{\mathrm{a}}$ and $\mathrm{d} N_{\mathrm{T}} / \operatorname{dlog} D_{\mathrm{a}}$ with a cutoff diameter of $\sim 1 \mu \mathrm{m}$ were derived.

\subsection{Meteorological parameter measurement}

Meteorological parameters were recorded during the entire campaign using a weather sensor (Lufft WS600-UMB) installed on the rooftop at the same height and a few meters away from the UV-APS inlet (Fig. 1b). These measurements were made concurrently with the UV-APS measurements. The weather station was capable of recording temperature, dew point temperature, relative humidity, precipitation intensity, wind speed, wind direction, and air pressure, and was set to record these parameters at $5 \mathrm{~min}$ intervals with time synchronized to the UV-APS measurement clock. The meteorological data obtained at this site were compared with data obtained from another weather station (Vaisala WXT520) installed in the vicinity. The scatter plots between the data 
(10 min averages) obtained from both these weather stations exhibited very strong agreement for all the meteorological parameters measured/recorded (average $R^{2} \geq 0.95$ ).

\subsection{SEM analysis}

The samples for scanning electron microscopy (SEM) analysis were collected on $25 \mathrm{~mm}$ diameter Nucleopore ${ }^{\circledR}$ polycarbonate filter paper with pore sizes of 5 and $0.2 \mu \mathrm{m}$ using a two-stage filtering method as described by Valsan et al. (2015). All samples were collected for an approximate duration of $60 \mathrm{~min}$ at an average flow rate of $5 \mathrm{~L} \mathrm{~min}^{-1}$ and were stored in an air-tight container at $4{ }^{\circ} \mathrm{C}$ until the SEM analysis was carried out. More than 100 individual particles analyzed from samples collected on five occasions during the entire campaign were investigated using two different scanning electron microscopes - (a) Quanta FEG 200 located at the Sophisticated Analytical Instrument Facility (SAIF) and (b) Hitachi S 4A00 located at the Chemical Engineering Department of the Indian Institute of Technology Madras. Before loading the filter paper onto the sample holders, they were cut into small squares of $\sim 1 \mathrm{~cm}^{2}$ and sputter-coated with gold particles. The biological aerosol particles were identified purely based on their morphological features adopting the method suggested by Matthias-Maser and Jaenicke (1991, 1994). A detailed description of sample collection and analysis was given elsewhere (Valsan et al., 2015).

\section{Results and discussions}

\subsection{Campaign overview}

Figure 2 shows the temporal evolution and variability of the several meteorological parameters, FBAPs, and TAP properties observed throughout the measurement campaign during the SW monsoon season at Munnar. Several observations regarding the meteorological conditions during the campaign at Munnar can be made. The predominant wind direction was observed to be westerly/southwesterly (Fig. 1), which is characteristic of the monsoon season and brings a nearly clean marine influx (laden with dust and sea salt particles; Vinoj and Satheesh, 2003; Satheesh and Srinivasan, 2002; Vinoj et al., 2014; Prospero, 1979) over the continent marked by the presence of persistent rainfall, high relative humidity $(\mathrm{RH})$, higher wind speeds, and lower temperatures. During this period, diurnal variations in temperature and relative humidity were very small and temperatures approached the dew point. On a few occasions, however, northerly winds were recorded, marked by relatively lower wind speeds, lower RH levels, higher temperatures, and reduced rainfall. During northerly winds, the temperature exhibited more pronounced diurnal variations compared to the relative humidity. The average meteorological parameters (arithmetic mean \pm standard deviation) recorded during the entire mea- surement period were $(840 \pm 1.3) \mathrm{hPa}$ absolute pressure, $(17.2 \pm 1.4)^{\circ} \mathrm{C}$ ambient temperature, $(96.4 \pm 5.7) \%$ relative humidity, $(2.8 \pm 1.3) \mathrm{m} \mathrm{s}^{-1}$ local wind speed, $(270)^{\circ}$ local wind direction (vector mean weighted by wind speed), and (4188) $\mathrm{mm}$ accumulated rainfall.

The total of more than 5 months of bioaerosol measurements with high time and size resolution was performed at this site for two contrasting seasons - monsoon (dominated by southwesterly winds) and winter (dominated by northeasterly winds). In this study, we present the results from this field campaign carried out during the SW monsoon season, whereas the detailed results from the winter campaign from the same measurement site will be presented in a follow-up study. We first discuss the characteristic features of the time series as a broad overview of the observed concentration levels, variability, and trends in $N_{\mathrm{T}}$ and $N_{\mathrm{F}}$. Figure $2 \mathrm{f}, \mathrm{g}, \mathrm{h}$, i, and $\mathrm{j}$ show the time series of geometric mean diameter $\left(D_{\mathrm{g}}\right), N_{\mathrm{F}}$, $N_{\mathrm{F}} / N_{\mathrm{T}}, N_{\mathrm{T}}, \mathrm{FBAP}$ and TAP 3-D size distribution measured with the UV-APS for the entire campaign.

Throughout the measurement period the hourly averaged $D_{\mathrm{g}}$ time series consistently remained in the range of $\sim 2$ $4 \mu \mathrm{m}$, with almost no diurnal variation. During the second half of the campaign, the $D_{\mathrm{g}}$, however, exhibited relatively high variability, with an average mean diameter of $2.6 \pm 0.7 \mu \mathrm{m}$. Unlike the $N_{\mathrm{T}}$ and $N_{\mathrm{F}}$ the variability in $D_{\mathrm{g}}$ did not seem to be affected by the meteorological parameters, except for wind direction (see Sect. 3.4.1) on a few occasions. The total coarse particle number concentration, $N_{\mathrm{T}}$, exhibited high and consistent variability during the entire measurement period, however, with no distinct diurnal cycle. Averaged (arithmetic mean \pm standard deviation) $N_{\mathrm{T}}$ over the entire measurement period was observed to be $1.8 \pm 1.5 \mathrm{~cm}^{-3}$, with the lowest and highest concentrations of $0.01 \mathrm{~cm}^{-3}$ and $8.6 \mathrm{~cm}^{-3}$, respectively. The monthly averaged $N_{\mathrm{T}}$ concentration (Fig. S4) exhibited a decreasing trend from June to $\mathrm{Au}-$ gust as the monsoon progressed (Table 2). In contrast, $N_{\mathrm{F}}$ exhibited less pronounced but episodic peaks in the time series during the majority of the measurement period, resulting in a campaign arithmetic mean of $0.02 \pm 0.02 \mathrm{~cm}^{-3}$. The highest $N_{\mathrm{F}}$ concentration of $\sim 0.52 \mathrm{~cm}^{-3}$ was observed in June, prior to the onset of monsoon rainfall, whereas the lowest $N_{\mathrm{F}}$ concentration $\left(<0.0002 \mathrm{~cm}^{-3}\right)$ was consistently observed on more than one occasion during the months of July and August. The monthly averaged $N_{\mathrm{F}}$ concentrations are listed in Table 2.

The time series of the relative contribution of FBAPs to TAP numbers, $N_{\mathrm{F}} / N_{\mathrm{T}}$, exhibited a similar trend in temporal variability as displayed by $N_{\mathrm{F}}$ for most of the campaign. The extreme values of $N_{\mathrm{F}} / N_{\mathrm{T}}$ observed on a few occasions corresponded to low values of $N_{\mathrm{T}}$, implying a negative correlation between $N_{\mathrm{T}}$ and $N_{\mathrm{F}} / N_{\mathrm{T}}$ during these measurements. Huffman et al. (2010) also reported a similar negative correlation between $N_{\mathrm{T}}$ and $N_{\mathrm{F}} / N_{\mathrm{T}}$ at a semi-urban site in central Europe, indicating that the variability in $N_{\mathrm{F}} / N_{\mathrm{T}}$ was associated with changes in $N_{\mathrm{T}}$ concentrations. The campaign overview 

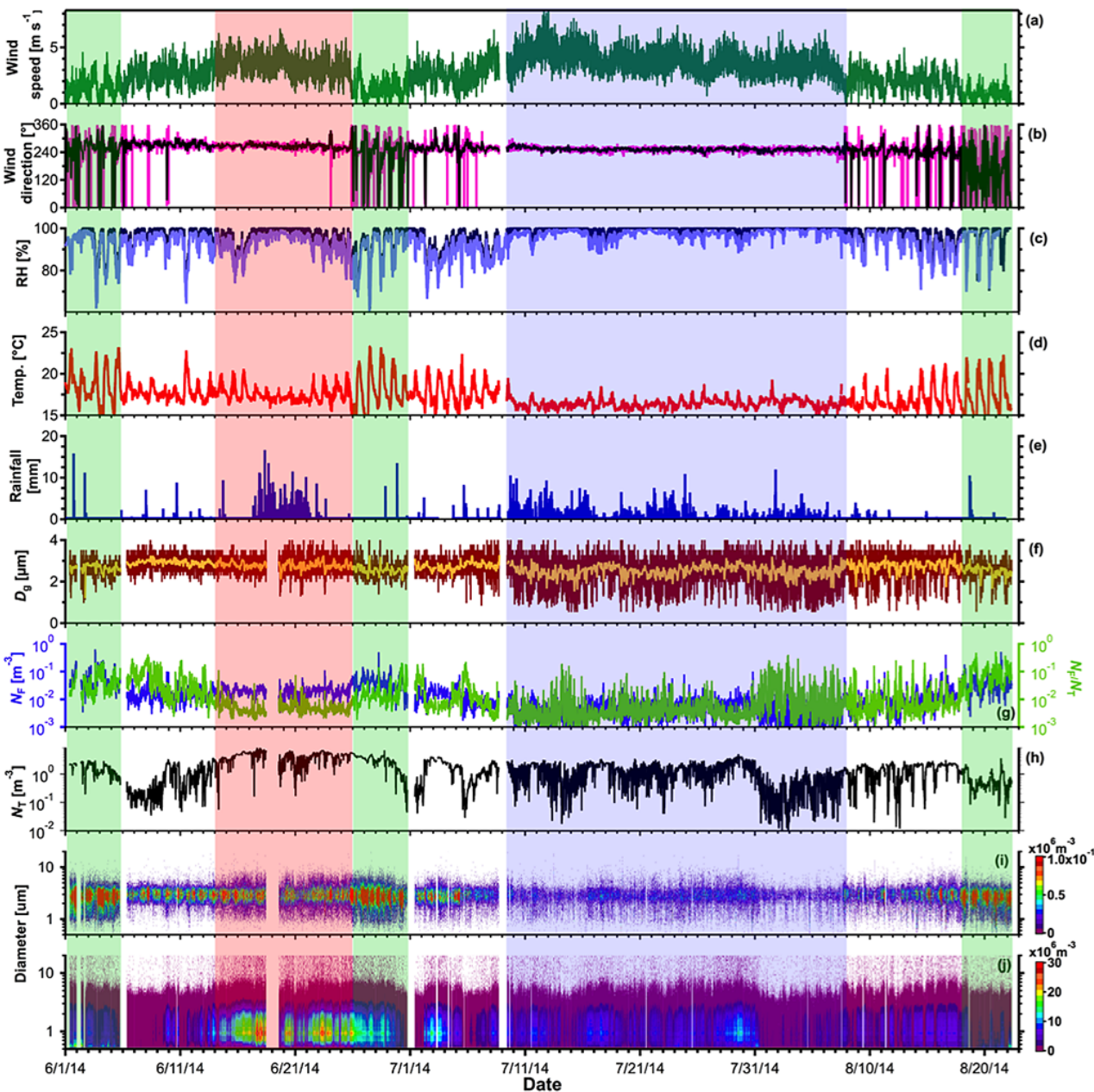

Figure 2. Time series of measured meteorological parameters, parameters derived from FBAPs, and total particle number size distribution measurements using UV-APS: (a) wind speed, (b) wind direction, 5 min average (magenta) and 1 h average (black), (c) relative humidity, (d) temperature, (e) rainfall, (f) geometric mean diameter $\left(D_{\mathrm{g}}\right), 5 \mathrm{~min}$ average (dark red) and $1 \mathrm{~h}$ average (yellow), (g) FBAP number concentration $\left(N_{\mathrm{F}}\right.$; blue) and relative contribution of FBAP to TAP $\left(N_{\mathrm{F}} / N_{\mathrm{T}}\right.$; green $)$, (h) TAP number concentration $\left(N_{\mathrm{T}}\right)$, (i) a contour plot of FBAP number size distribution $\left(\mathrm{d} N / \mathrm{d} \log D_{\mathrm{F}}\right)$, and $(\mathbf{j})$ a contour plot of TAP number size distribution $\left(\mathrm{d} N / \mathrm{d} \log D_{\mathrm{T}}\right)$. The $\operatorname{shadowed}$ block represents the different focus periods (red for dusty; green for high bio; blue for clean: please refer to the text for more details).

(including individual months) of FBAP mass concentrations and the 3-D size distribution for every 5 min of UV-APS measurement are shown in Fig. S5.

\subsubsection{Particle number and mass concentrations}

The number and mass concentration measurements carried out at Munnar over the course of the campaign are shown in Fig. 3 and tabulated in Table 2. The box plots show statistical representation of $5 \mathrm{~min}$ averaged data of the time series. Over the entire measurement period the monthly mean of $N_{\mathrm{T}}$ varied by a factor of $\sim 3$ from a minimum in $\mathrm{Au}-$ gust $\left(0.96 \mathrm{~cm}^{-3}\right)$ to a maximum in June $\left(2.7 \mathrm{~cm}^{-3}\right.$; Fig. $\left.3 \mathrm{a}\right)$. The variability of $N_{\mathrm{T}}$ was also found to be highest in the month of June, as can be seen from the size of the 5-95th percentiles, which was also reflected in the high variability of $N_{\mathrm{T}}$ for the entire measurement period. During the initial phase of the southwest monsoon season, the predominant westerly/southwesterly winds are known to transport the mineral dust, which constitute a large fraction of coarsemode (also in larger diameter sizes of fine-mode fractions) TAP concentration over the Indian continental region (Vinoj et al., 2010, 2014; Li and Ramanathan, 2002; Satheesh and Srinivasan, 2002; Vinoj and Satheesh, 2003). As the monsoon progresses the persistent rainfall can cause the washout of these dust particles along the path of monsoonal rain, thus reducing the coarse-mode TAP concentration (Pranesha and Kamra, 1997a, b; Radke et al., 1980; Moorthy et al., 1991). The monthly arithmetic mean and median average of $N_{\mathrm{T}}$ did not exhibit significant differences. The monthly mean values of $N_{\mathrm{F}}$ varied by a factor of $\sim 4$, with moderate variability during the entire campaign (Fig. 3b). Similar to $N_{\mathrm{T}}$, the 
Table 2. Integrated number concentrations and mass concentrations of coarse TAP and FBAP $(\sim 1-20 \mu \mathrm{m})$ : arithmetic mean and median for each month and for the entire measurement campaign.

\begin{tabular}{llrrrr}
\hline Number & & June & July & August & Campaign \\
\hline$N_{\mathrm{T}}\left(\mathrm{cm}^{-3}\right)$ & Mean & 2.66 & 1.54 & 0.96 & 1.77 \\
& Median & 2.45 & 1.48 & 0.73 & 1.44 \\
\hline$N_{\mathrm{F}}\left(\mathrm{cm}^{-3}\right)$ & Mean & 0.03 & 0.007 & 0.015 & 0.017 \\
& Median & 0.02 & 0.006 & 0.007 & 0.01 \\
\hline$N_{\mathrm{F}} / N_{\mathrm{T}}(\%)$ & Mean & 0.03 & 0.01 & 0.03 & 0.02 \\
& Median & 0.01 & & 0.01 & 0.01 \\
\hline Mass & & June & July & August & Campaign \\
\hline$M_{\mathrm{T}}\left(\mu \mathrm{g} \mathrm{m}^{-3}\right)$ & Mean & 10.61 & 6.15 & 4.15 & 7.17 \\
& Median & 9.58 & 5.55 & 2.8 & 5.57 \\
\hline \multirow{2}{*}{$M_{\mathrm{F}}\left(\mu \mathrm{g} \mathrm{m}^{-3}\right)$} & Mean & 0.42 & 0.11 & 0.18 & 0.24 \\
& Median & 0.33 & 0.09 & 0.1 & 0.15 \\
\hline$M_{\mathrm{F}} / M_{\mathrm{T}}(\%)$ & Mean & 0.09 & 0.03 & 0.08 & 0.06 \\
& Median & 0.04 & 0.02 & 0.03 & 0.03 \\
\hline
\end{tabular}

monthly mean average value and variability in $N_{\mathrm{F}}$ was highest in the month of June, with a mean of $0.03 \pm 0.03 \mathrm{~cm}^{-3}$ and a 95th percentile value of $0.086 \mathrm{~cm}^{-3}$. The lowest average concentration in $N_{\mathrm{F}}\left(0.007 \pm 0.006 \mathrm{~cm}^{-3}\right)$ was observed in the month of July, with relatively lower variability as compared to other months of the field measurement campaign. Unlike $N_{\mathrm{T}}$, the arithmetic mean and median average of $N_{\mathrm{F}}$ for individual months exhibited a significant difference, as can be seen from the box plot shown in Fig. 3b. The variability of $N_{\mathrm{F}} / N_{\mathrm{T}}$ showed a similar temporal pattern to that displayed by $N_{\mathrm{F}}$, except that the campaign-averaged mean $N_{\mathrm{F}}$ concentration was higher than that of August, whereas the campaign-averaged mean $N_{\mathrm{F}} / N_{\mathrm{T}}$ was observed to be lower than the mean calculated for August. The median and mean for $N_{\mathrm{F}} / N_{\mathrm{T}}$ over the course of campaign were $\sim 1$ and $2 \%$, respectively (Fig. 3c). The average values of $N_{\mathrm{F}} / N_{\mathrm{T}}$ over this part of the globe were lower than previously investigated sites (Huffman et al., 2010, 2012; Bowers et al., 2009; Schumacher et al., 2013; Matthias-Maser and Jaenicke, 1995; Matthias-Maser et al., 2000; Gabey et al., 2010).

Although the UV-APS measures particle numbers, the average size-resolved particle mass can also be estimated by assuming the particle density to be equal to $1 \mathrm{~g} \mathrm{~cm}^{-3}$ (Huffman et al., 2010, 2012). Based on this, the mass concentrations of FBAPs $\left(M_{\mathrm{F}}\right)$ and TAP $\left(M_{\mathrm{T}}\right)$ are presented in Fig. 3. The monthly mean values of $M_{\mathrm{T}}$ exhibited similar trend and temporal variability to that shown by $N_{\mathrm{T}}$, with an overall decrease in $M_{\mathrm{T}}$ as the campaign progressed (Fig. 3d). The campaign mean $M_{\mathrm{T}}$ at Munnar was $\sim 7 \mu \mathrm{g} \mathrm{m}^{-3}$, which was comparable to the values reported from a central European city $\left(M_{\mathrm{T}} \sim 7.3 \mu \mathrm{g} \mathrm{m}^{-3}\right)$ and higher than the concentration of $M_{\mathrm{T}}\left(\sim 2.5 \mu \mathrm{g} \mathrm{m}^{-3}\right)$ reported from a pristine Amazonian rainforest region measured during the wet season (Huffman et al., 2010, 2012). The monthly mean values of $M_{\mathrm{F}}$, on the other hand, did not exhibit a similar pattern to that shown by $M_{\mathrm{T}}$, but followed a temporal pattern similar to that shown by $N_{\mathrm{F}}$ (Fig. 3e). The highest mean mass concentration of $M_{\mathrm{F}}$ $\left(\sim 0.4 \mu \mathrm{g} \mathrm{m}^{-3}\right)$ observed during June was $\sim 3$ and 2 times lower than the concentrations observed at a central European city $\left(\sim 1.26 \mathrm{\mu g} \mathrm{m}^{-3}\right)$ and pristine Amazonian rainforest $\left(\sim 0.85 \mu \mathrm{g} \mathrm{m}^{-3}\right)$, respectively. The higher difference between mean and median values of the box plots indicates the higher temporal variability. The median and mean for $M_{\mathrm{F}} / M_{\mathrm{T}}$ over the course of the entire measurement period were 6 and $3 \%$, respectively, which is relatively low compared to previously reported studies for various other environments (Huffman et al., 2010, 2012; Artaxo and Hansson, 1995; Schumacher et al., 2013; Fig. 3f). On average, the relative contribution of FBAPs to TAP coarse-mode particle mass was $\sim 3$ times higher $(\sim 6 \%)$ than its contribution to coarse-mode particle number concentration $(\sim 2 \%)$. This is consistent with the observations that FBAPs show enhanced prevalence among the larger aerosol particles (Huffman et al., 2010).

\subsubsection{Diurnal patterns}

The average diurnal trends for 3 individual months and the entire measurement campaign were analyzed. Figure 4 shows the mean FBAP values for each hour of the day for 3 individual months in the campaign, and Fig. S6 shows the corresponding TAP plots. Overall $N_{\mathrm{F}}$ exhibited a moderate diurnal pattern with a consistent early morning $(06: 00 \mathrm{~h})$ peak at $\sim 3 \mu \mathrm{m}$ (Fig. 4a) except for the month of July, where this early morning peak was absent. A very weak peak during late evening $(20: 00 \mathrm{~h})$ in FBAP concentration at $\sim 3 \mu \mathrm{m}$ was observed in the month of July. In the month of June, the average diurnal $N_{\mathrm{F}}$ concentration started increasing early in the evening $(\sim 18: 00 \mathrm{~h})$, which gradually increased through the night, reaching a maximum at $\sim 06: 00 \mathrm{~h}$, and started decreasing thereafter as the day progressed. A similar diurnal pattern was also observed in August but without high FBAP concentrations in the evening hours. In general, the weak diurnal pattern observed in $N_{\mathrm{F}}$ during the month of July seemed to follow the weak diurnal patterns in RH and temperature in the presence of persistent rainfall observed during July. The early morning peak at $\sim 3 \mu \mathrm{m}$ on the diurnal scale was also reported from a pristine Amazonian rainforest environment (Huffman et al., 2012). Corresponding average size distributions for the entire measurement period will be discussed in detail in the following section. The diurnal variations of $N_{\mathrm{T}}$ (Fig. S6), on the other hand, were very distinct from those of $N_{\mathrm{F}}$. The size-resolved $\mathrm{d} N_{\mathrm{T}} / \mathrm{d} \log D_{\mathrm{a}}$ for each individual month exhibited a consistent and flat concentration profile at $<1 \mu \mathrm{m}$. Previous studies where a similar instrument was used have reported that pronounced diurnal variations in $N_{\mathrm{T}}$ are strongly coupled with diurnal variations in meteorological variables, especially mixing layer depth (Garland et al., 2009; Raatikainen et al., 2014; Du et al., 2013). The ab- 

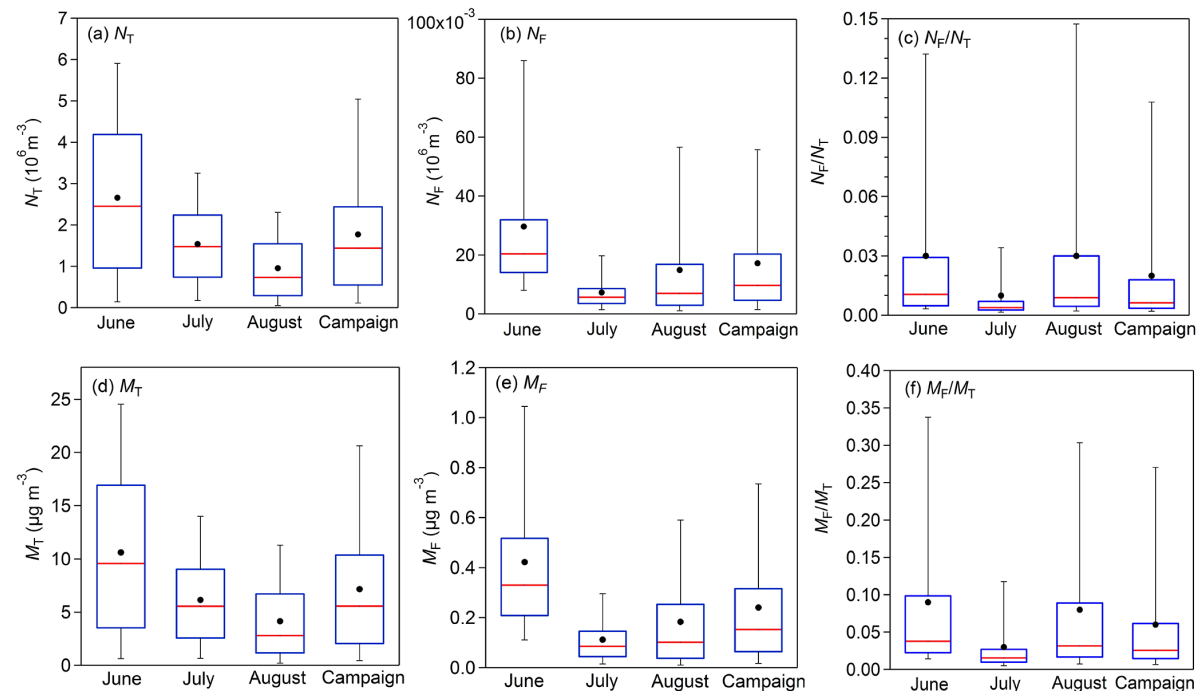

Figure 3. Statistical distribution of integrated $(\sim 1-20 \mu \mathrm{m})$ FBAP and TAP number and mass and their ratios measured during each month (June-August) of the SW monsoon season and averaged over the entire measurement campaign carried out at Munnar as box whisker plots: (a) TAP number concentration $\left(N_{\mathrm{T}}\right)$, (b) FBAP number concentration $\left(N_{\mathrm{F}}\right)$, (c) contribution of FBAP number concentration to TAP number concentration $\left(N_{\mathrm{F}} / N_{\mathrm{T}}\right)$, (d) TAP mass concentration $\left(M_{\mathrm{T}}\right)$, (e) FBAP mass concentration $\left(M_{\mathrm{F}}\right)$ and (f) contribution of FBAP to TAP mass concentration $\left(M_{\mathrm{F}} / M_{\mathrm{T}}\right)$.

sence of pronounced diurnal variations in $N_{\mathrm{T}}$ at this particular site may be a result of weak dependence of coarse-mode TAP concentrations on meteorological parameters combined with persistent rainfall causing the washout of these particles (Radke et al., 1980; Raatikainen et al., 2014; Kanawade et al., 2014; Shika et al., 2016). This also indicates the absence of any strong and localized source of anthropogenic emissions during most of the campaign period. Diurnal patterns of $N_{\mathrm{F}} / N_{\mathrm{T}}$ more or less followed the same pattern as that of $N_{\mathrm{F}}$ during all the measurement months. The distinct diurnal pattern in $N_{\mathrm{F}}$ and $N_{\mathrm{T}}$ supports the fact that the sources of TAP and FBAP were different over this region.

The diurnal trends in $M_{\mathrm{F}}$ and $M_{\mathrm{T}}$ for individual months and the campaign average were also analyzed and are shown in Figs. S7 and S8. The monthly averaged diurnal trends in $M_{\mathrm{F}}$ for individual months and the entire campaign exhibited a trend similar to that shown by corresponding to $N_{\mathrm{F}}$. However, the prominent peak in $\mathrm{d} M_{\mathrm{F}} / \operatorname{d} \log D_{\mathrm{a}}$ was observed at a higher diameter $(\sim 3-4 \mu \mathrm{m})$. The concentration peak of $<1 \mu \mathrm{m}$ observed in $N_{\mathrm{T}}$ shifted to the higher diameter range of $\sim 3-4 \mu \mathrm{m}$ as an increase in mass is more associated with the presence of coarse-mode particles. The distribution of $M_{\mathrm{T}}$ (Fig. S8), however, exhibited a distinctly different trend compared to both $M_{\mathrm{F}}$ and $N_{\mathrm{T}}$. The distinct diurnal patterns of $M_{\mathrm{F}}$ and $M_{\mathrm{T}}$ showed a much lower relative contribution of FBAPs to TAP mass as compared to other observational sites (Huffman et al., 2010, 2012; Matthias-Maser and Jaenicke, 1995).

\subsubsection{Size distribution of particle number and mass}

Figure 5 shows the number and mass size distributions for TAPs and FBAPs averaged over the entire measurement period. The TAP number size distribution, $\mathrm{d} N_{\mathrm{T}} / \operatorname{d} \log D_{\mathrm{a}}$, was generally broad and dominated by a peak at the lower end of the measured size range of the number size distribution ( $D_{\mathrm{a}} \approx 0.9 \mu \mathrm{m}$; Fig. 5a). In $\mathrm{d} N_{\mathrm{T}} / \operatorname{d} \log D_{\mathrm{a}}$, the concentrations exhibited a significant decrease above diameter $\sim 3 \mu \mathrm{m}$, with a long tail extending on the right-hand side of the distribution. This peak may be comprised of mineral dust and sea salt particles, as also evident from SEM images (please refer to Sect. 3.3) and as also reported by the previous studies investigating aerosol composition over India during the monsoon season (Vinoj et al., 2014; Moorthy et al., 1991; Vinoj and Satheesh, 2003; Satheesh and Srinivasan, 2002; Li and Ramanathan, 2002). A similar peak in $\mathrm{d} N_{\mathrm{T}} / \operatorname{d} \log D_{\mathrm{a}}$ at $D_{\mathrm{a}} \approx 0.9 \mu \mathrm{m}$ was observed in a pristine Amazonian rainforest during the wet season and was attributed to mineral dust (Huffman et al., 2012; Fig. 5b). The corresponding monthly plots of $\mathrm{d} N_{\mathrm{T}} / \mathrm{d} \log D_{\mathrm{a}}$ are shown in Fig. S9 and exhibited a similar qualitative number size distribution pattern to that of the campaign-averaged TAP number size distribution. Averaged over the entire measurement period, the mass size distribution, $\mathrm{d} M_{\mathrm{T}} / \operatorname{d} \log D_{\mathrm{a}}$ (Fig. 5c), exhibited a broad peak at $\sim 2.6 \mu \mathrm{m}$, with an extended tail to the left side of the mass size distribution. The corresponding monthly averaged $\mathrm{d} M_{\mathrm{T}} / \mathrm{d} \log D_{\mathrm{a}}$ are shown in Fig. S10 and appeared similar to the campaign-averaged TAP mass size distribution. For accurate representation of mass size distribution, the unitnormalized mass distribution of $D_{\mathrm{a}}$ plotted in Fig. $5 \mathrm{c}$ and d is 

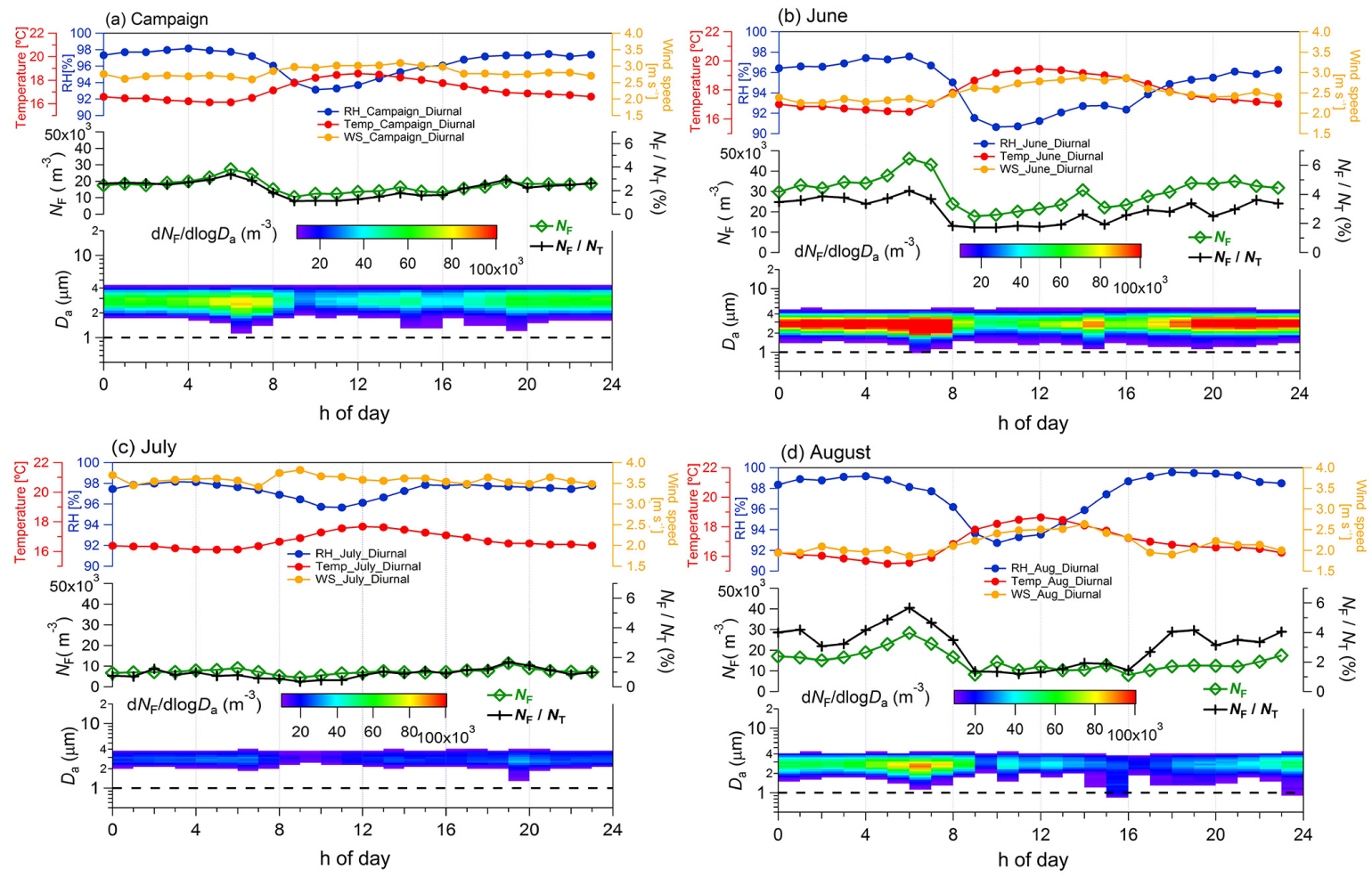

Figure 4. Diurnal cycles of observed meteorological parameters, FBAP number concentrations $\left(N_{\mathrm{F}}\right)$ and size distributions averaged over individual months of measurement and the entire campaign (hourly mean values plotted against the local time of day). The upper portion of each panel shows the observed meteorological parameters: relative humidity (\%; blue), temperature $\left({ }^{\circ} \mathrm{C}\right.$; red), and wind speed (m $\mathrm{s}^{-1}$; orange on the right axis). The middle panel shows the integrated FBAP number concentration $\left(\sim 1-20 \mu \mathrm{m} ; N_{\mathrm{F}}\right)$ on the left axis (green) and the FBAP fraction of the TAP number $\left(N_{\mathrm{F}} / N_{\mathrm{T}}\right)$ on the right axis (black). The lower portion of each panel FBAP number size distribution (3-D plot) plotted against the hour of the day on the $x$ axis and the aerodynamic diameter on the $y$ axis and color scaled for $\mathrm{d} N_{\mathrm{F}} / \mathrm{d} \log D_{\mathrm{a}}$ indicate the concentration. Dashed black lines in the lower portion of each panel at $1.0 \mu \mathrm{m}$ show the particle size cutoff diameter below which fluorescent particles were not considered to be FBAPs due to potential interference with non-biological aerosol particles. (a) averaged over the entire campaign, (b) June, (c) July, and (d) August. Please refer to the figures in the Supplement for corresponding TAP plots.

expected to shift to a larger particle size with increased area under the curve (Huffman et al., 2010; DeCarlo et al., 2004).

The campaign-averaged number size distribution of FBAPs (Fig. 5b) exhibited a monomodal shape with a much narrower peak than the TAP number size distribution, with a dominant mode at $D_{\mathrm{a}} \approx 2.8 \mu \mathrm{m}$, which was consistent throughout the measurement period. The corresponding monthly mean FBAP number size distributions are shown in Fig. S11. As reported by Huffman et al. (2010), multiple and broader peaks in $\mathrm{d} N_{\mathrm{F}} / \mathrm{d} \log D_{\mathrm{a}}$ are most likely to originate from different sources and biological species. In the present study, however, we did not find multiple peaks in investigated FBAP number size distribution, suggesting that observed FBAPs comprised the particles from similar or identical sources. The overall qualitative appearance of the average FBAP number size distribution is similar to that which has been reported by previous measurements. For a semi-urban site in central Europe, Huffman et al. (2010) reported an average FBAP peak at $3.2 \mu \mathrm{m}$. Gabey et al. (2010) observed a peak at $\sim 2.5 \mu \mathrm{m}$ at a tropical rain forest site in Borneo. From a pristine Amazonian rainforest site during the wet season, Huffman et al. (2012) reported a peak at $\sim 2.3 \mu \mathrm{m}$. For another pristine observational site in a boreal forest in Finland, Schumacher et al. (2013) reported a peak in FBAP number size distribution at $\sim 3 \mu \mathrm{m}$. A peak at $\sim 3 \mu \mathrm{m}$ was also observed by Healy et al. (2014) at a rural site in Killarney national park, Ireland. This dominant peak in the range of 2 $3 \mu \mathrm{m}$ in FBAP number size distribution is strongly attributed to the fungal spores over the continent as reported by numerous previous researchers (Huffman et al., 2010, 2012; Schumacher et al., 2013, Li et al., 2011; Artaxo and Hansson, 1995; Healy et al., 2014; Gabey et al., 2010, 2013; Toprak and Schnaiter, 2013). Recently, Valsan et al. (2015) investigated the morphological characteristics of PBAPs from the same site during the non-monsoon season and found that fungal spores constituted the major fraction of PBAPs and nominally ranged in the size range of $\sim 3-10 \mu \mathrm{m}$, which roughly translates into an equivalent aerodynamic diameter of $2-5 \mu \mathrm{m}$ (assuming the particles to be a prolate spheroid). The scanning electron microscopy images obtained from the 

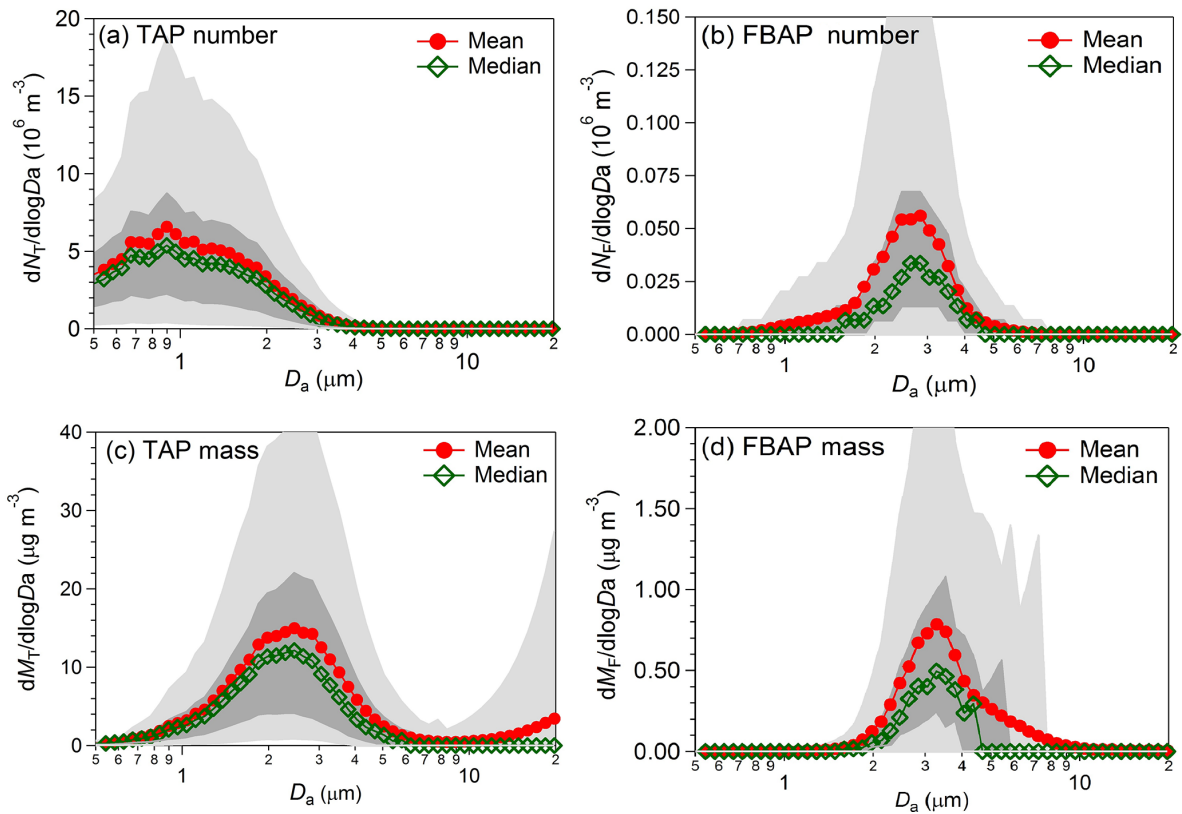

Figure 5. Particle number size and unit-normalized number size and mass size distributions averaged over the entire measurement campaign carried out at Munnar. The lower and upper parts of the dark and light shaded areas represent the 5th, 25th, 75th, and 95th percentiles, respectively. (a) TAP number $\left(\mathrm{d} N_{\mathrm{T}} / \mathrm{d} \log D_{\mathrm{a}}\right)$, (b) FBAP number $\left(\mathrm{d} N_{\mathrm{F}} / \mathrm{d} \log D_{\mathrm{a}}\right)$, (c) total mass $\left(\mathrm{d} M_{\mathrm{T}} / \mathrm{d} \log D_{\mathrm{a}}\right)$, and (d) FBAP mass $\left(\mathrm{d} M_{\mathrm{F}} / \mathrm{d} \log D_{\mathrm{a}}\right)$.

Table 3. Comparison with other online measurements carried out under various environmental conditions across the globe.

\begin{tabular}{|c|c|c|c|c|c|c|c|c|c|}
\hline Sl no.: & Location & Land use & Measurement period & Season & Instrument & $\begin{array}{l}\text { FBAP number } \\
\text { concentration }\end{array}$ & $\begin{array}{l}\text { Total number } \\
\text { concentration }\end{array}$ & $\begin{array}{l}\text { Number } \\
\text { ratio }(\%)\end{array}$ & Reference \\
\hline 1 & Mainz, central Europe & Semi-urban & August-December 2006 & & UVAPS & $3 \times 10^{-2} \mathrm{~cm}^{-3}$ & $1.05 \mathrm{~cm}^{-3}$ & 4 & Huffman et al. (2010) \\
\hline 2 & Central Amazonia rainforest & Tropical rainforest & February-March 2008 & & UVAPS & $7.3 \times 10^{-2} \mathrm{~cm}^{-3}$ & $0.33 \mathrm{~cm}^{-3}$ & 24 & Huffman et al. (2012) \\
\hline 3 & Manchester, UK & Urban & December 2009 & & WIBS-3 & $\begin{array}{l}2.9 \times 10^{-4} \mathrm{~cm}^{-3} \text { (FL1) } \\
5.2 \times 10^{-4} \mathrm{~cm}^{-3} \text { (FL2) } \\
1.1 \times 10^{-5} \mathrm{~cm}^{-3} \text { (FL3) }\end{array}$ & $1.38 \times 10^{-2} \mathrm{~cm}^{-3}$ & $\begin{array}{l}2.1 \\
3.7 \\
7.8\end{array}$ & Gabey et al. (2011) \\
\hline 4 & Central France & Rural & 22 June-3 July 2010 & & WIBS-3 & $\begin{array}{l}1.2 \times 10^{-2} \mathrm{~cm}^{-3}(280 \mathrm{~nm}) \\
9.5 \times 10^{-2} \mathrm{~cm}^{-3}(370 \mathrm{~nm})\end{array}$ & & & Gabey et al. (2013) \\
\hline 5 & Helinski, Finland & Urban & $\begin{array}{l}\text { February } 2012 \text { (winter) } \\
\text { June-August } 2012 \text { (summer) }\end{array}$ & $\begin{array}{l}\text { Winter } \\
\text { Summer } \\
\text { Summer }\end{array}$ & $\begin{array}{l}\text { BioScout } \\
\text { UVAPS }\end{array}$ & $\begin{array}{l}1 \times 10^{-2} \mathrm{~cm}^{-3} \\
2.8 \times 10^{-2} \mathrm{~cm}^{-3} \\
1.3 \times 10^{-2} \mathrm{~cm}^{-3}\end{array}$ & & $\begin{array}{l}23 \\
6 \\
8\end{array}$ & Saari et al. (2015) \\
\hline 6 & Colorado, USA & Pine forest & June-July 2011 & $\begin{array}{l}\text { Dry period } \\
\text { Wet period }\end{array}$ & $\begin{array}{l}\text { WIBS-3 } \\
\text { WIBS-4 }\end{array}$ & & & $\begin{array}{l}5.8 \\
15.2\end{array}$ & Crawford et al. (2014) \\
\hline 7 & Finland & Rural forest & August 2009-April 2011 & $\begin{array}{l}\text { Spring } \\
\text { Summer } \\
\text { Fall } \\
\text { Winter }\end{array}$ & UVAPS & $\begin{array}{l}1.5 \times 10^{-2} \mathrm{~cm}^{-3} \\
4.6 \times 10^{-2} \mathrm{~cm}^{-3} \\
2.7 \times 10^{-2} \mathrm{~cm}^{-3} \\
0.4 \times 10^{-2} \mathrm{~cm}^{-3}\end{array}$ & $\begin{array}{l}0.43 \mathrm{~cm}^{-3} \\
0.45 \mathrm{~cm}^{-3} \\
0.41 \mathrm{~cm}^{-3} \\
0.47 \mathrm{~cm}^{-3}\end{array}$ & $\begin{array}{l}4.4 \\
13 \\
9.8 \\
1.1\end{array}$ & Schumacher et al. (2013) \\
\hline & Colorado, USA & Rural, semi-arid & 2011-2012 & $\begin{array}{l}\text { Spring } \\
\text { Summer } \\
\text { Fall } \\
\text { Winter }\end{array}$ & UVAPS & $\begin{array}{l}1.5 \times 10^{-2} \mathrm{~cm}^{-3} \\
3 \times 10^{-2} \mathrm{~cm}^{-3} \\
1.7 \times 10^{-2} \mathrm{~cm}^{-3} \\
0.53 \times 10^{-2} \mathrm{~cm}^{-3}\end{array}$ & $\begin{array}{l}0.73 \mathrm{~cm}^{-3} \\
0.44 \mathrm{~cm}^{-3} \\
0.28 \mathrm{~cm}^{-3} \\
0.2 \mathrm{~cm}^{-3}\end{array}$ & $\begin{array}{l}2.5 \\
8.8 \\
5.7 \\
3\end{array}$ & \\
\hline 8 & Karlsruhe, Germany & Semi-rural & April 2010-April 2011 & & WIBS-4 & $3.1 \times 10^{-2} \mathrm{~cm}^{-3}$ & $0.583 \mathrm{~cm}^{-3}$ & 7.34 & Toprak and Schnaiter (2013) \\
\hline 9 & Nanjing, China & Sub-urban & October-November 2013 & Fall & WIBS-4 & $\begin{array}{l}0.6 \mathrm{~cm}^{-3} \text { (FL1) } \\
3.4 \mathrm{~cm}^{-3} \text { (FL2) } \\
2.1 \mathrm{~cm}^{-3} \text { (FL3) }\end{array}$ & $13.1 \mathrm{~cm}^{-3}$ & $\begin{array}{l}4.6 \\
25.3 \\
15.6\end{array}$ & Yu et al. (2016) \\
\hline
\end{tabular}

filter samples collected during this field campaign showed the strong presence of a variety of fungal spores in the size range of 6-10 $\mu \mathrm{m}$ (aerodynamic diameter 3-5 $\mu \mathrm{m}$; discussed below; Fig. 11). As an overview of the comparison, the FBAP concentration values observed at Munnar are compared to the FBAP concentration ranges obtained using similar online measurement techniques from diverse environmental conditions across the globe, and the details are tabulated in Table 3 . The campaign-averaged FBAP mass size distribution is shown in Fig. 5d, which nominally appeared bimodal with a very sharp primary peak at $D_{\mathrm{a}} \approx 3.2 \mu \mathrm{m}$ and a very broad but small second mode at $D_{\mathrm{a}} \approx 4 \mu \mathrm{m}$. The corresponding monthly mean FBAP mass size distributions are shown in Fig. S12. The FBAP mass size distribution for individual months exhibited a similar qualitative shape to that of the campaign-averaged mass size distribution.

Figure 6 shows the size-resolved ratio of overall FBAP/TAP for the course of measurement and correspond- 


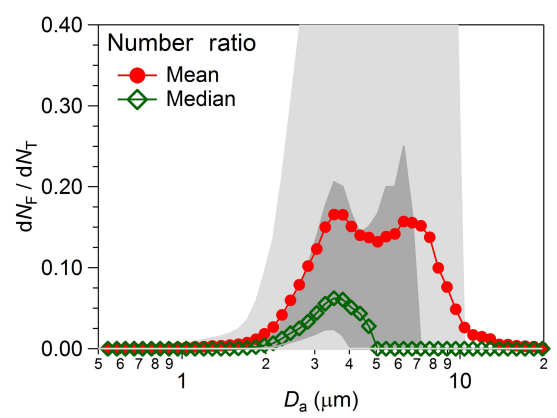

Figure 6. Size distribution of the FBAP to TAP ratio averaged over the entire measurement period carried out at Munnar $\left(\mathrm{d} N_{\mathrm{F}} / \mathrm{d} \log D_{\mathrm{a}}=\mathrm{d} M_{\mathrm{F}} / \mathrm{d} \log D_{\mathrm{a}}\right)$. The lower and upper parts of the dark and light shaded areas represent the 5th, 25th, 75th, and 95th percentiles, respectively.

ing monthly ratios are shown in Fig. S13. The relative contribution of FBAPs $\left(\mathrm{d} N_{\mathrm{F}}\right)$ to TAPs $\left(\mathrm{d} N_{\mathrm{T}}\right)$ in each size bin could be used to derive the relative contribution of biological particles to total aerosol particles at each size. As reported by Huffman et al. (2010), the assumption of the unit density of each particle implies that the value of the $\mathrm{d} N_{\mathrm{F}} / \mathrm{d} N_{\mathrm{T}}$ ratio would invariably be equal to $\mathrm{d} M_{\mathrm{F}} / \mathrm{d} M_{\mathrm{T}}$. The integrated $N_{\mathrm{F}} / N_{\mathrm{T}}$ and $M_{\mathrm{F}} / M_{\mathrm{T}}$, however, would have the distinct values. As can be seen from Figs. 6 and S13, a considerable quantitative and qualitative difference in mean (red) and median (green) curves was consistently observed in all individual months, which likely is the result of poor counting statistics and very high variability in TAP number concentrations. Based on the results presented by Huffman et al. (2010), the mean (red) curve best represents the $N_{\mathrm{F}} / N_{\mathrm{T}}$ ratios at the upper particle sizes. The mean $N_{\mathrm{F}} / N_{\mathrm{T}}$ ratio curves for individual months and for the entire campaign exhibited two dominant peaks persistently in the particle size range $\sim 3-4$ and $\sim 6-8 \mu \mathrm{m}$. The first prominent peak in the $\mathrm{d} N_{\mathrm{F}} / \mathrm{d} N_{\mathrm{T}}$ distribution at 3-4 $\mu \mathrm{m}$ comprised $15-16 \%$, while the second peak at $6-8 \mu \mathrm{m}$ represented $\sim 14-15 \%$ of the FBAP material in TAP over the entire measurement period (Fig. 6).

\subsection{Focus periods}

The characteristic properties of FBAP and, specifically, TAP number concentration exhibited strong temporal variability, which could be attributed to changes in prevailing meteorological conditions during the monsoon season at Munnar. The following three distinct focus periods during the campaign are highlighted as follows.

1. A "dusty" focus period was identified when the prevailing wind was predominantly westerly/southwesterly and air masses mainly came from the Arabian Sea. These were laden with sea salt and dust particles during the start of the monsoon, which dominate the coarsemode fraction of atmospheric aerosols (Vinoj et al.,
2014; Li and Ramanathan, 2002) originating from western Asia, northern Africa, and the Arabian region (Vinoj et al., 2014) and not from local anthropogenic sources. In this campaign, such a dusty period was observed between 14 and 25 June 2014, which was consistent with the description given above and also based on the SEM images of the dust collected in this period (see Sect. 3.5 below). This period was marked by an accumulated rainfall of $\sim 1015 \mathrm{~mm}$, average relative humidity of $94.4 \pm 6.5 \%$, average temperature of $17.7 \pm 1.5^{\circ} \mathrm{C}$, and average wind speed of $2.8 \pm 1.3 \mathrm{~m} \mathrm{~s}^{-1}$ (maximum wind speed of $6.7 \mathrm{~m} \mathrm{~s}^{-1}$ ).

2. A "clean" focus period was observed during the latter half of the monsoon season when wind direction was still predominantly westerly/southwesterly and air masses originated over the Arabian Sea. During this period, which was observed from 9 July to $7 \mathrm{Au}-$ gust 2014, FBAP and TAP concentrations were extremely low with very low variability. This clean period was associated with persistent rainfall (accumulated rainfall of $2650 \mathrm{~mm}$ ), average relative humidity of $99.5 \pm 1.4 \%$, average temperature of $16.4 \pm 0.5^{\circ} \mathrm{C}$, and average wind speed of $3.7 \pm 1 \mathrm{~m} \mathrm{~s}^{-1}$ (maximum wind speed of $8.3 \mathrm{~m} \mathrm{~s}^{-1}$ ).

3. A "high bio" focus period comprised three discrete events of high FBAP concentrations observed between 1 and 5 June, 26 and 30 June, and 18 and 22 August 2014. This period is marked by distinct metrological parameters compared to the clean period: accumulated rainfall $194 \mathrm{~mm}$, average relative humidity $93.4 \pm 8.4 \%$, average temperature $18.0 \pm 2.4{ }^{\circ} \mathrm{C}$, and average wind speed $1.2 \pm 0.8 \mathrm{~m} \mathrm{~s}^{-1}$ (with a maximum wind speed of $4.6 \mathrm{~m} \mathrm{~s}^{-1}$ ). It is suggested that these high bio periods are due to high variability in relative humidity and temperature and the movement of air masses with relatively low wind speed over densely vegetated region located north of the observational site.

\subsubsection{Particle number and mass concentrations}

The statistical distributions of $N_{\mathrm{T}}, N_{\mathrm{F}}, M_{\mathrm{T}}$, and $M_{\mathrm{F}}$, and the corresponding ratios for three different focus periods (dusty, clean, and high bio) are shown in Fig. 7 and tabulated in Table 4. Each of the focus periods discussed here was not of equal duration. The average total particle number concentration, $N_{\mathrm{T}}$, showed a decrease of $\sim 70 \%$ from the dusty period to the clean period ( $\sim 4.2$ and $\sim 1.3 \mathrm{~cm}^{-3}$, respectively), whereas the $N_{\mathrm{T}}$ concentration during the high bio period was $\sim 1.8 \mathrm{~cm}^{-3}$. The high $N_{\mathrm{T}}$ concentration during the dusty period caused the high variability between the 5th and 95th percentiles in $N_{\mathrm{T}}$ when averaged over the entire campaign period (Fig. 3a). The fraction of dust in coarse-mode aerosol, which is observed to be very high during pre-monsoon and the first few days from the onset of monsoon rainfall, gradu- 
Table 4. Integrated number concentrations and mass concentrations of coarse TAP and FBAP $(\sim 1-20 \mu \mathrm{m})$ : arithmetic mean and median for each focus period (dusty, clean and high bio).

\begin{tabular}{|c|c|c|c|c|}
\hline Number & & Dusty & Clean & High bio \\
\hline \multirow[t]{2}{*}{$N_{\mathrm{T}}\left(\mathrm{cm}^{-3}\right)$} & Mean & 4.2 & 1.27 & 1.78 \\
\hline & Median & 4.36 & 1.15 & 1.4 \\
\hline \multirow[t]{2}{*}{$N_{\mathrm{F}}\left(\mathrm{cm}^{-3}\right)$} & Mean & 0.02 & 0.005 & 0.05 \\
\hline & Median & 0.019 & 0.004 & 0.038 \\
\hline \multirow[t]{2}{*}{$N_{\mathrm{F}} / N_{\mathrm{T}}$} & Mean & 0.01 & 0.01 & 0.05 \\
\hline & Median & & & 0.03 \\
\hline Mass & & Dusty & Clean & High bio \\
\hline \multirow[t]{2}{*}{$M_{\mathrm{T}}\left(\mu \mathrm{g} \mathrm{m}^{-3}\right)$} & Mean & 16.34 & 5.12 & 7.7 \\
\hline & Median & 16.84 & 4.28 & 5.85 \\
\hline \multirow[t]{2}{*}{$M_{\mathrm{F}}\left(\mu \mathrm{g} \mathrm{m}^{-3}\right)$} & Mean & 0.36 & 0.08 & 0.58 \\
\hline & Median & 0.33 & 0.05 & 0.47 \\
\hline \multirow[t]{2}{*}{$M_{\mathrm{F}} / M_{\mathrm{T}}$} & Mean & 0.02 & 0.03 & 0.12 \\
\hline & Median & 0.02 & 0.01 & 0.08 \\
\hline
\end{tabular}

ally decreased as the monsoon progressed, likely as a result of washout and wet deposition due to persistent rainfall in the path of air masses (Hirst, 1953; Madden, 1997; Burge and Rogers, 2000). The $M_{\mathrm{T}}$ exhibited a similar pattern to that of $N_{\mathrm{T}}$ during three distinct focus periods, with an average mass concentration of $\sim 16.3, \sim 5.1$, and $\sim 7.7 \mu \mathrm{g} \mathrm{m}^{-3}$ for the dusty, clean, and high bio periods, respectively (Fig. 7d).

The mean $N_{\mathrm{F}}$ concentration during the high bio period (Fig. 7b) was $0.05 \pm 0.04 \mathrm{~cm}^{-3}$ with high variability in the higher concentration range $\left(0.06-0.13 \mathrm{~cm}^{-3}\right)$, as is evident from the distance between the 75th and 95th percentiles. The $N_{\mathrm{F}}$ was found to be relatively stable during the dusty period, with an average concentration of $\sim 0.02 \pm 0.008 \mathrm{~cm}^{-3}$. The mean $N_{\mathrm{F}}$ concentration was found to be an order of magnitude lower during the clean period $\left(0.005 \pm 0.004 \mathrm{~cm}^{-3}\right)$ as compared to the high bio period, whereas the corresponding decrease in $N_{\mathrm{T}}$ from the dusty to clean periods ( $\sim$ by a factor of 3) was not of a similar magnitude. The following is the hypothesis proposed for such concentration differences in $N_{\mathrm{F}}$ and $N_{\mathrm{T}}$ during the three distinct periods: during the clean period the predominant wind direction was westerly/southwesterly and air masses came from the Arabian Sea, bringing clean marine influx marked by persistent rainfall. As a result, the coarse-mode aerosol fractions $\left(N_{\mathrm{F}}\right.$ and $N_{\mathrm{T}}$ ) emitted locally were efficiently removed; however, the sea salt particles present in the air masses that came from the Arabian Sea contributed to TAP number concentration (see Sect. 3.3). In addition to the efficient wet removal of FBAP due to persistent rainfall, the high RH level (average 99.5\%) causes the dew formation that further inhibits the spore release, in turn reducing the FBAP concentration (Schumacher et al., 2013; Jones and Harrison, 2004). The mean values of
$M_{\mathrm{F}}$ exhibited trends similar to those shown by $N_{\mathrm{F}}$, with the highest mass concentration of $0.58 \mu \mathrm{g} \mathrm{m}^{-3}$ during the high bio period, which decreased by $\sim 86 \%\left(0.08 \mu \mathrm{g} \mathrm{m}^{-3}\right)$ during the clean period. As anticipated, the relative contribution of FBAP in TAP during the dusty and clean periods was almost negligible, with a $N_{\mathrm{F}} / N_{\mathrm{T}}$ ratio of $\sim 1 \%$, whereas during the high bio period the relative FBAP number and mass contribution to the corresponding TAP was $\sim 5$ and $12 \%$, respectively.

\subsubsection{Size distribution of particle number and mass concentration}

Figure 8a highlights the $\mathrm{d} N_{\mathrm{F}} / \operatorname{d} \log D_{\mathrm{a}}$ during three distinct focus periods, and corresponding $\mathrm{d} N_{\mathrm{T}} / \operatorname{d} \log D_{\mathrm{a}}$ are shown in Fig. S14. In general, $\mathrm{d} N_{\mathrm{F}} / \mathrm{d} \log D_{\mathrm{a}}$ during each focus period exhibited a pattern similar to that of the campaign average.

The $\mathrm{d} N_{\mathrm{F}} / \operatorname{d} \log D_{\mathrm{a}}$ averaged over the high bio period exhibited a very prominent and sharp peak at $\sim 2.5-3 \mu \mathrm{m}$. The corresponding $\mathrm{d} N_{\mathrm{F}} / \mathrm{d} \log D_{\mathrm{a}}$ during the dusty and clean periods also exhibited a similar bell-shaped distribution with less prominent peaks owing to the relatively lower FBAP concentrations as compared to the high bio period. Unlike previously reported studies (Huffman et al., 2010; 2012), the peak in $\mathrm{d} N_{\mathrm{F}} / \operatorname{dlog} D_{\mathrm{a}}\left(D_{\mathrm{a}} \approx 3 \mu \mathrm{m}\right)$ was not reflected in $\mathrm{d} N_{\mathrm{T}} / \operatorname{d} \log D_{\mathrm{a}}$, mostly due to the relatively lower contribution of FBAPs in coarse-mode TAP number concentration. As seen from Fig. S14, the total aerosol particle number size distribution, $\mathrm{d} N_{\mathrm{T}} / \mathrm{d} \log D_{\mathrm{a}}$, during all three focus periods exhibited an almost similar pattern to that of campaignaveraged $\mathrm{d} N_{\mathrm{T}} / \operatorname{d} \log D_{\mathrm{a}}$, with higher concentrations peaking at lower diameters.

The FBAP mass size distribution (Fig. 8b) during the dusty period was dominated by bimodal peaks, with a prominent peak at $\sim 3 \mu \mathrm{m}$ and a relatively less pronounced peak in the range of $\sim 4-6 \mu \mathrm{m}$ showing a broader tail on the right side of the distribution curve. The $\mathrm{d} M_{\mathrm{F}} / \mathrm{d} \log D_{\mathrm{a}}$, during the clean period, exhibited similar bimodal peaks with extended shoulders in the diameter range from $\sim 4$ to $7 \mu \mathrm{m}$. The $\mathrm{d} M_{\mathrm{F}} / \operatorname{d} \log D_{\mathrm{a}}$ distribution during the high bio period was distinctly different compared to the other two focus periods discussed above, with a prominent monomodal peak at $\sim 3 \mu \mathrm{m}$. The primary peak observed in $\mathrm{d} M_{\mathrm{F}} / \operatorname{d} \log D_{\mathrm{a}}$ in the range of $\sim 3$ to $4 \mu \mathrm{m}$ was consistent during individual months and different focus periods. TAP mass size distribution (Fig. S15) exhibited a similar qualitative pattern to that of campaign-averaged $\mathrm{d} M_{\mathrm{T}} / \operatorname{dog} D_{\mathrm{a}}$, with a peak between $\sim 2.5$ and $3.5 \mu \mathrm{m}$ and an extended tail on the right side, which gradually increased for $D_{\mathrm{a}}>13 \mu \mathrm{m}$. The statistics representing the 5 th, 25 th, 75 th, and 95 th percentiles for $\mathrm{d} N_{\mathrm{F}} / \operatorname{dlog} D_{\mathrm{a}}$ and $\mathrm{d} M_{\mathrm{F}} / \operatorname{dlog} D_{\mathrm{a}}$ during individual focus periods are shown in Figs. S16 and S17.

The size-resolved ratio of FBAP to TAP particles averaged for three distinct focus periods is shown in Fig. 9. As is evident from the figure, the largest fraction of FBAP parti- 

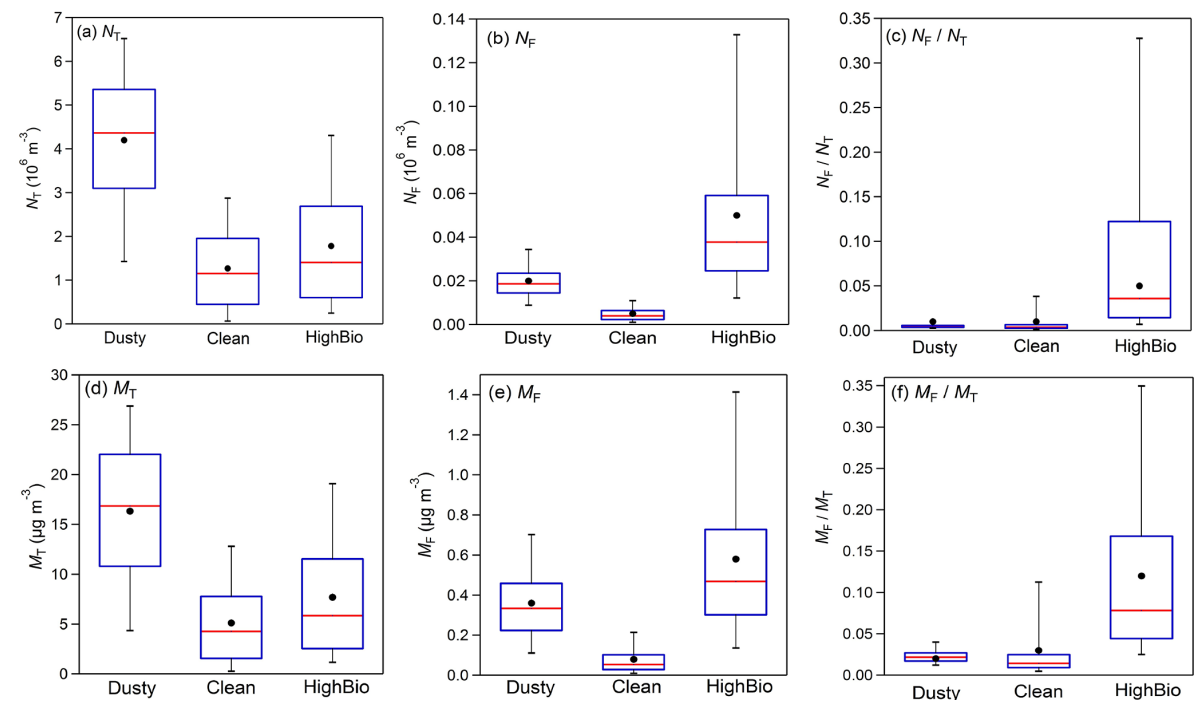

Figure 7. Statistical distribution of integrated $(\sim 1-20 \mu \mathrm{m})$ FBAP and TAP number and mass contribution of $N_{\mathrm{F}}$ to $N_{\mathrm{T}}$, and $M_{\mathrm{F}}$ to $M_{\mathrm{T}}$ averaged over each distinct focus period (dusty, clean, and high bio; please refer to the text for definitions related to each focus period) measurements carried out at Munnar as box whisker plots: (a) TAP number concentration $\left(N_{\mathrm{T}}\right)$, (b) FBAP number concentration $\left(N_{\mathrm{F}}\right)$, (c) contribution of FBAP number concentration to TAP number concentration $\left(N_{\mathrm{F}} / N_{\mathrm{T}}\right)$, (d) TAP mass concentration $\left(M_{\mathrm{T}}\right)$, (e) FBAP mass concentration $\left(M_{\mathrm{F}}\right)$, and contribution of FBAP mass concentration to TAP mass concentration $\left(M_{\mathrm{T}} / M_{\mathrm{F}}\right)$.
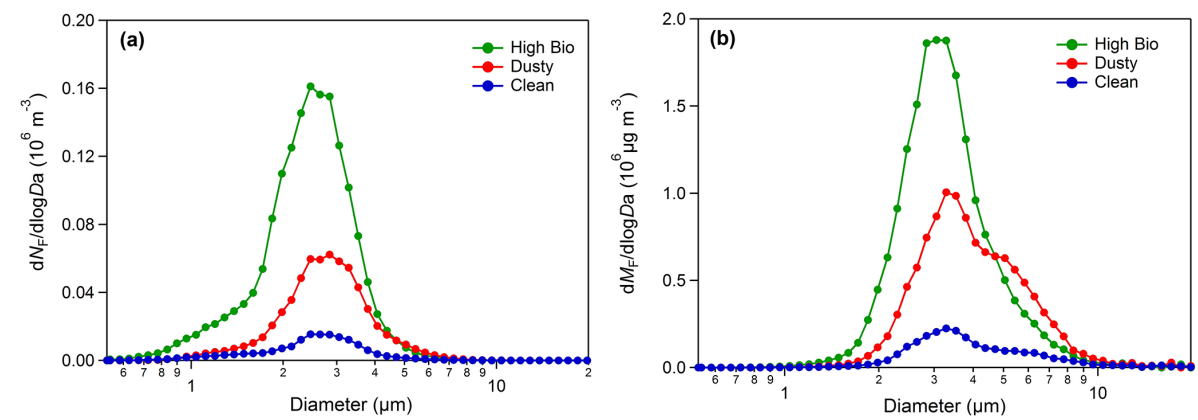

Figure 8. FBAP number $\left(\mathrm{d} N_{\mathrm{F}} / \mathrm{d} \log D_{\mathrm{a}}\right)$ and mass $\left(\mathrm{d} M_{\mathrm{F}} / \mathrm{d} \log D_{\mathrm{a}}\right)$ size distribution averaged over each distinct focus period during the measurement campaign carried out at Munnar. (a) Number size distribution and (b) mass size distribution.

cles during the dusty period occurred between $\sim 6$ and $9 \mu \mathrm{m}$ $(\sim 20 \%)$, with a relatively small $(\sim 7 \%)$ contribution in the diameter range of $\sim 3-4 \mu \mathrm{m}$. The fact that $N_{\mathrm{F}} / N_{\mathrm{T}}$ is near zero for particle sizes below $\sim 1.5 \mu \mathrm{m}$ is in line with previous observations reported from a semi-urban site in central Europe and during the wet season of pristine Amazonian rainforest (Huffman et al., 2010, 2012). During the clean period the maximum contribution of FBAPs to TAP number concentration decreased to $\sim 10.5 \%$ in the diameter range of $\sim 6-9 \mu \mathrm{m}$, but the peak appeared at $\sim 3-4 \mu \mathrm{m}$ and remained almost consistent, with a relative contribution of $\sim 8 \%$, whereas during the high bio period the maximum contribution of FBAP to TAP occurred between a broader size range of $\sim 3-8 \mu \mathrm{m}$, with a contribution range of $\sim 28-19 \%$. Interestingly, during the high bio period, the highest contribution of FBAPs to TAP number concentration occurred at $D_{\mathrm{a}} \approx 3.5 \mu \mathrm{m}$, as opposed to the other two focus periods, when the highest contribution was observed in the larger diameter ranges of $\sim 6-8 \mu \mathrm{m} . N_{\mathrm{F}} / N_{\mathrm{T}}$ was consistently found to be very low, with values approaching zero for the diameter beyond $13 \mu \mathrm{m}$, indicating that FBAPs constituted an extremely small fraction of total aerosol particles (Huffman et al., 2010, 2012). The two prominent peaks observed during the focus periods were clearly evident in campaign-averaged $\mathrm{d} N_{\mathrm{F}} / \mathrm{d} N_{\mathrm{T}}$ (Fig. 6; peaks at $\sim 3.5$ and $6 \mu \mathrm{m}$ ).

\subsubsection{Diurnal patterns}

A prominent early morning peak in $N_{\mathrm{F}}$ during the high bio period in the diameter range of 1.5-3 $\mu \mathrm{m}$ was observed from 06:00 to 08:00, which was clearly reflected in campaignaveraged diurnal patterns at the same hour of the day. The diurnal variations in $N_{\mathrm{F}}$ during the dusty and clean periods 

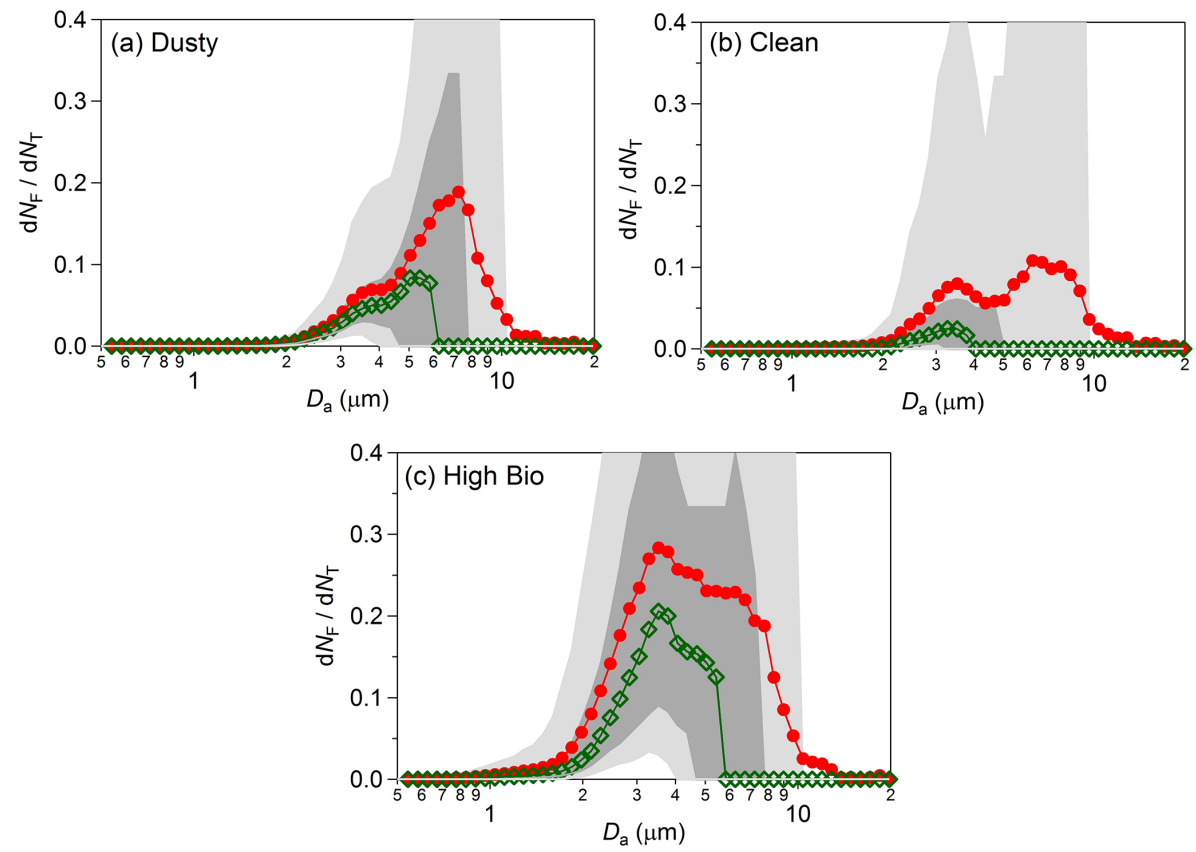

Figure 9. Size distribution of the FBAP to TAP ratio averaged over each distinct focus period during the measurements carried out at Munnar $\left(\mathrm{d} N_{\mathrm{F}} / \mathrm{d} \log D_{\mathrm{a}}=\mathrm{d} M_{\mathrm{F}} / \mathrm{d} \log D_{\mathrm{a}}\right)$. The lower and upper parts of the dark and light shaded areas represent the 5th, 25th, 75th, and 95th percentiles, respectively: (a) dusty, (b) clean, and (c) high bio.

were not so pronounced (Fig. 10) as compared to the variations during the high bio period. During the dusty period, $N_{\mathrm{F}}$ showed a slightly high concentration starting from $\sim 17: 00$ (lowest panel Fig. 10a) and persistently remained high until early morning without any variations, whereas during the clean period, the $N_{\mathrm{F}}$ concentration consistently remained flat throughout $24 \mathrm{~h}$. As reported by Huffman et al. (2012), the emission and dispersal of bioaerosols are strongly coupled with environmental variables such as solar radiation, temperature, and relative humidity. Each of these variables exhibited relatively pronounced diurnal variations during the high bio period (upper panel, Fig. 10c). It has been well documented that relative humidity, in particular, plays an important role in active wet discharge of fungal spores (Adhikari et al., 2006; Burch and Levetin, 2002; Elbert et al., 2007; Jones and Harrison, 2004; Quintero et al., 2010; Zhang et al., 2010), which constitutes a major fraction of atmospheric bioaerosols (Ansari et al., 2015; Bauer et al., 2008; Bowers et al., 2013; Fröhlich-Nowoisky et al., 2009; Sesartic and Dallafior, 2011; Spracklen and Heald, 2014). The meteorological parameters exhibited significant diurnal variations during the high bio period, where RH decreased to a level of $\sim 60-80 \%$, which is considered to be favorable for release of the fungal spores (Jones and Harrison, 2004; Santarpia et al., 2013). During the dusty and clean periods, the persistence of high RH values in the range of $\sim 90-100 \%$ might have inhibited the active wet discharge of fungal spores (Schumacher et al., 2013), thus resulting in the weak diurnal variation in $N_{\mathrm{F}}$. Unlike $N_{\mathrm{F}}, N_{\mathrm{T}}$ remained nearly flat, without any pronounced diurnal variations during three distinct focus periods (Fig. S18). The corresponding diurnal cycle of FBAP mass concentrations and 3-D size distributions for three focus periods is shown in Fig. S19. $M_{\mathrm{F}}$ exhibited similar diurnal patterns to that of $N_{\mathrm{F}}$ during three distinct focus periods. $M_{\mathrm{T}}$ and $N_{\mathrm{T}}$ remained flat during the dusty period, but exhibited a slightly pronounced diurnal pattern during the clean and high bio periods between 09:00 and 16:00 (Fig. S20).

\subsection{SEM images}

Figure 11 shows representative SEM images of different biological particle types often observed during the SW monsoon season at Munnar. The details about the sampling techniques, instrument used, etc. for obtaining these bioaerosol images are discussed in details by Valsan et al. (2015). Note that these images are being presented here to showcase the particle types consistently observed throughout the measurement period and not for quantitative purposes. The presence of mineral dust and sea salt particles confirms marine influence of the air mass sampled. Many particles observed by SEM were most likely Basidiospores. The appearance of small protuberances on their surfaces suggests that the spores (e.g., Fig. 11a and c) most likely belonged to the Hydnaceae family (Grand and Vandyke, 1976; Valsan et al., 2015). The Basidiospores shown in Fig. 11b and c were seen in abundance in all the samples collected during the campaign. Some of the spores observed appeared to be coated with salt particles (Fig. 11e) and might have been carried from a dis- 

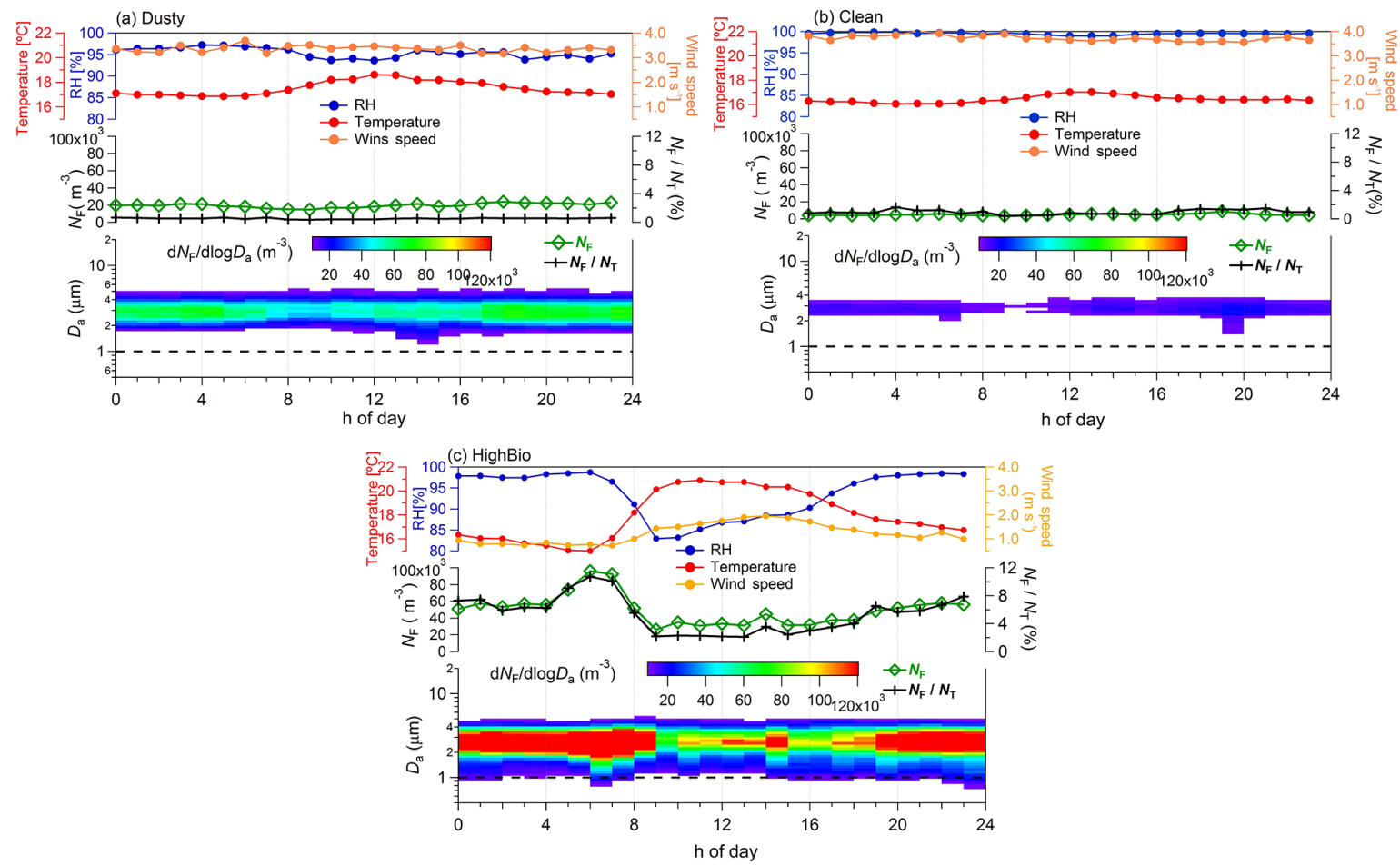

Figure 10. Diurnal cycles of observed meteorological parameters, FBAP number concentrations $\left(N_{\mathrm{F}}\right)$ and size distributions averaged over each distinct focus period identified during measurements carried out at Munnar (hourly mean values plotted against the local time of day). The upper portion of each panel shows the observed meteorological parameters: relative humidity (\%; blue), temperature $\left({ }^{\circ} \mathrm{C}\right.$; red), and wind speed $\left(\mathrm{m} \mathrm{s}^{-1}\right.$; orange on the right axis). The middle panel shows the integrated FBAP number concentration $\left(\sim 1-20 \mu \mathrm{m} ; N_{\mathrm{F}}\right)$ on the left axis (green) and the FBAP fraction of the TAP number $\left(N_{\mathrm{F}} / N_{\mathrm{T}}\right)$ on the right axis (black). The lower portion of each panel FBAP number size distribution (3-D plot) plotted against the hour of the day on the $x$ axis, aerodynamic diameter on the $y$ axis, and color, is scaled for $\mathrm{D} N_{\mathrm{F}} / \operatorname{d} \log D_{\mathrm{a}}$ and indicates the concentration. Dashed black lines in the lower portion of each panel at $1.0 \mu \mathrm{m}$ show the particle size cutoff diameter below which fluorescent particles were not considered to be FBAPs due to potential interference with non-biological aerosol particles. (a) Dusty, (b) clean, and (c) high bio. Please refer to the figures in the Supplement for corresponding TAP plots.

tant source by the SW monsoon winds. The spores shown in Fig. 11d and f most likely appeared to be spores of Ascomycota division. The particle shown in Fig. 11g was most likely a mineral dust particle sampled during high dusty episode. Similar particles of varying size during the dusty episode were consistently observed during SEM analysis. Figure $11 \mathrm{~h}$ and $i$ shows the images of the typical sea salt particles observed during samples collected at Munnar during measurement campaign when wind predominantly came from a westerly/southwesterly direction travelling over the Indian Ocean and Arabian Sea.

\subsection{Meteorological correlations}

The results obtained with UV-APS data analysis during the campaign at Munnar were correlated with meteorological parameters to investigate factors responsible for bioaerosol release and their variations in the atmosphere.

\subsubsection{Impact of wind direction}

The wind rose diagrams scaled by $N_{\mathrm{F}}, D_{\mathrm{g}}$, and $D_{\mathrm{g}, \mathrm{T}}$ were also prepared for the entire measurement period and three distinct focus periods. These plots are similar to the traditional wind rose diagram (Fig. S21), except that, instead of wind speed, they are scaled by characteristic FBAP and TAP parameters, which indicate the frequency of occurrence of the respective parameter with respect to wind direction (Sherman et al., 2015). As seen from Fig. S21, the predominant wind direction during the entire campaign was westerly/southwesterly, with a frequency of occurrence of about $\sim 90 \%$. The wind speed broadly ranged between 2 and $5 \mathrm{~m} \mathrm{~s}^{-1}$ with no prominent diurnal variations. The overall wind direction and back-trajectory analysis (Fig. 1) shows that the sampled air masses may have originated over the Indian Ocean and then turned eastward after crossing the Equator and travelling several hundred kilometers over the Arabian Sea before reaching the observational site (Fig. 1). The predominant wind pattern during the dusty ( $>95 \%$ frequency of occurrence; $2-6 \mathrm{~m} \mathrm{~s}^{-1}$ ) and 

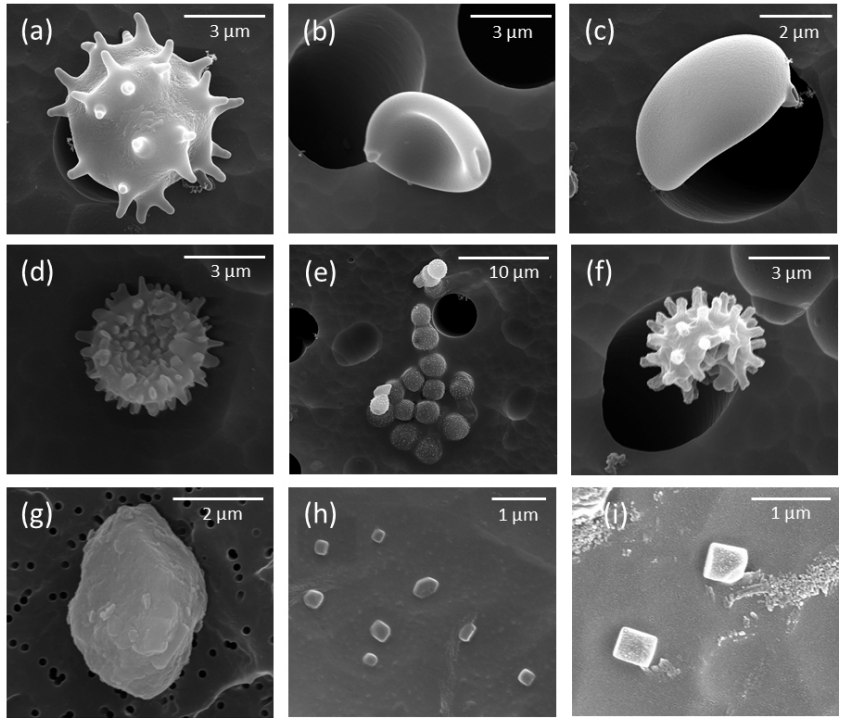

Figure 11. Scanning electron microscope images of the exemplary aerosol particles (FBAP and TAP) observed during the campaign at Munnar. The scale bar is shown at the top right corner of each image.

clean periods $\left(\sim 100\right.$ frequency of occurrence; $\left.2-6 \mathrm{~m} \mathrm{~s}^{-1}\right)$ was westerly/southwesterly, whereas during the high bio period, only $\sim 50 \%$ of the time did winds come from a westerly/southwesterly direction, and the rest comprised relatively slower $\left(0-2 \mathrm{~m} \mathrm{~s}^{-1}\right)$ winds from all other directions, with the highest contribution from northerly winds (Fig. S21).

The wind rose diagram scaled by FBAP number concentration is shown in Fig. 12. During the entire campaign the predominant wind showed that $\sim 85 \%$ of the time FBAP concentration occurred in the range of $0-0.05 \mathrm{~cm}^{-3}$ (Fig. 12a), occasionally exceeding $0.05 \mathrm{~cm}^{-3}$, and was contributed by westerly/southwesterly winds. The occurrence of relatively low FBAP concentrations during the entire campaign is coincidental with low concentration occurrence during the dusty $\left(0-0.05 \mathrm{~cm}^{3} ;>90 \%\right.$ frequency of occurrence) and clean $\left(<0.01 \mathrm{~cm}^{3} ; \sim 90 \%\right.$ frequency of occurrence) periods. During the high bio period the FBAP concentration, $>0.05 \mathrm{~cm}^{3}$, exhibited a $\sim 40 \%$ frequency of occurrence, of which $\sim 50 \%$ was contributed by predominant wind from the north and the northwest.

Similarly, the wind rose diagram scaled by geometric mean diameter $\left(D_{\mathrm{g}}\right)$ of $\mathrm{d} N_{\mathrm{F}} / \operatorname{dog} D_{\mathrm{a}}$ is shown in Fig. 13. The average size of the FBAP particles associated with westerly/southwesterly winds when analyzed for the entire campaign ranged between 2 and $4 \mu \mathrm{m}$, of which $\sim 65 \%$ of the time $D_{\mathrm{g}}$ was observed to be $\leq 3 \mu \mathrm{m}$. During the three focus periods the frequency of occurrence of FBAP particles in the higher size range $(3-4 \mu \mathrm{m})$ was strongly associated with the westerly/southwesterly winds (Figs. 13b-d). The corresponding wind rose diagram scaled by geometric mean diam-
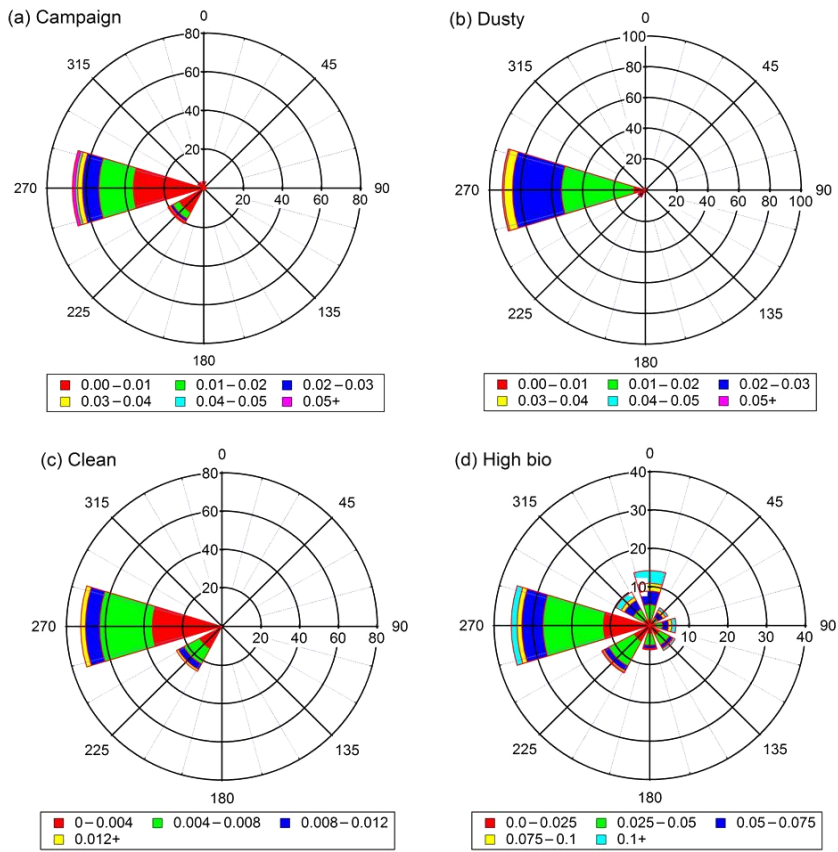

Figure 12. Wind rose diagram scaled over FBAP number concentration $\left(N_{\mathrm{F}}\right)$. These diagrams in a way are similar to the traditional wind rose diagram, except that they represent the $N_{\mathrm{F}}$ in this case instead of wind speed. These diagrams can be nominally interpreted as follows: for example, (a) shows that $\sim 52 \%$ of the frequency of occurrence of $N_{\mathrm{F}}$ concentrations in the range of $0-0.01 \mathrm{~cm}^{-3}$ was associated with westerly/southwesterly winds and, by contrast, (d) indicates that out of $\sim 18 \%$ of the frequency of occurrence of high concentrations $\left(N_{\mathrm{F}}>0.1 \mathrm{~cm}^{-3}\right), \sim 16 \%$ was associated with northerly/northwesterly winds. (a) Entire campaign, (b) dusty period, (c) clean period, and (d) high bio period. Note that the nonuniform scale of each panel has a unit of $\mathrm{cm}^{-3}$.

eter of $\mathrm{d} N_{\mathrm{T}} / \mathrm{d} \log D_{\mathrm{a}}\left(D_{\mathrm{g}, \mathrm{T}}\right)$ is shown in Fig. S22. During the entire measurement campaign the frequency of occurrence of $D_{\mathrm{g}, \mathrm{T}}$ in the size range of $0.8-0.9 \mu \mathrm{m}$ was $\sim 70 \%$ and was mostly associated with westerly/southwesterly winds. During the dusty period, particles in the size range of $0.8-0.9 \mu \mathrm{m}$ diameter contributed for $>95 \%$ frequency of occurrence for the entire size range, whereas during clean period $\sim 20 \%$ occurrence of the particles in the size range other than 0.8 $0.9 \mu \mathrm{m}$ were also observed. On the other hand, during the high bio period, total particles in the size range $0.5-0.8 \mu \mathrm{m}$ were observed with a $\sim 50 \%$ frequency of occurrence mostly dominated by northerly winds.

The FBAP concentration exhibited strong dependence on the wind direction for this observational site. During the high bio period the increase in frequency of occurrence of FBAP number concentrations $>0.1 \mathrm{~cm}^{-3}$ coincided with a lower wind speed coming from the north and northwest (Fig. 14a). During the high bio period, as in the case of the dusty and clean periods, the predominant wind pattern was westerly/southwesterly, but with a relatively low frequency 

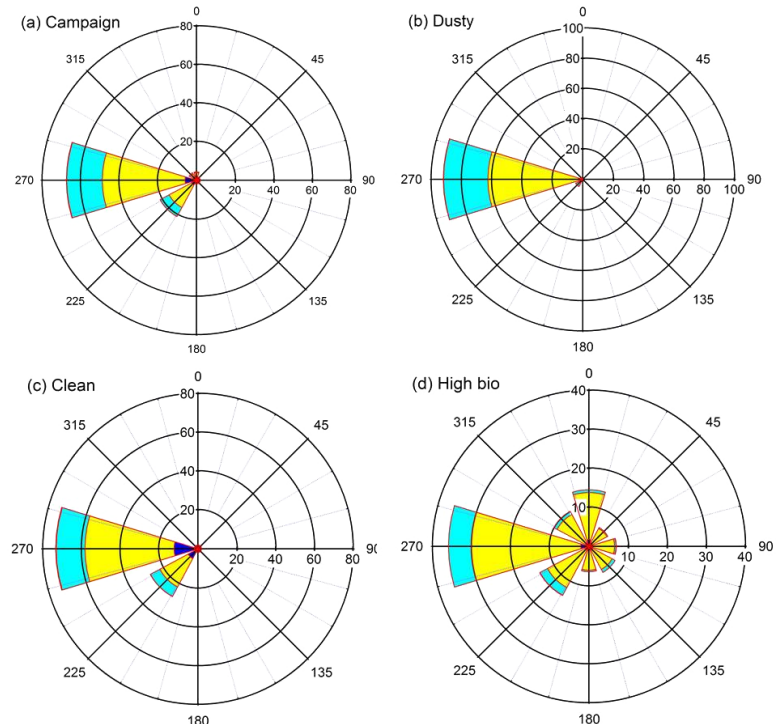

$1-2 \mu \mathrm{m} \quad \square$ 2-3 $\mu \mathrm{m} \quad \square$ 3-4 $\mu \mathrm{m} \quad \square 4+\mu \mathrm{m}$

Figure 13. Same as Fig. 12 but scaled by the geometric mean diameter $\left(D_{\mathrm{g}}\right)$ of $\mathrm{d} N_{\mathrm{F}} / \mathrm{d} \log D_{\mathrm{a}}$. (a) Entire campaign, (b) dusty period, (c) clean period, and (d) high bio period.

of occurrence as compared to the other two periods. To have a better understanding of the relative contribution of wind direction in high FBAP number concentrations during the high bio period, separate wind rose diagrams for FBAP concentrations $>0.1 \mathrm{~cm}^{-3}$ and $<0.1 \mathrm{~cm}^{-3}$ are shown in Fig. 14 . The FBAP number concentration $>0.1 \mathrm{~cm}^{-3}$ was associated with lower wind speed $\left(0-1 \mathrm{~m} \mathrm{~s}^{-1} ; \sim 80 \%\right.$ frequency of occurrence) and predominant northerly winds (Fig. 14a), as opposed to high wind speed $\left(2-5 \mathrm{~m} \mathrm{~s}^{-1}\right)$ and predominant westerly/southwesterly winds for the FBAP number concentration $<0.1 \mathrm{~cm}^{-3}$ (Fig. 14b). The northerly winds with lower wind speed coming over from densely vegetated regions in combination with local FBAP sources during the high bio period could be the strong reason for the build-up, resulting in a higher FBAP number concentration during this episode, whereas westerly/southwesterly winds were consistently marked by very low FBAP number concentrations, mostly owing to higher wind speeds. Furthermore, it might also be due to the fact that the air masses arrive at the observational site originating over a cleaner marine region, which may be a potential but weak source of bioaerosols combined with possible washout/wet deposition due to persistent rainfall during the transport. The frequency of occurrence of larger particles $(3-4 \mu \mathrm{m})$ during westerly/southwesterly winds was high compared to the northerly winds, where particles were mostly of smaller size $(1-3 \mu \mathrm{m})$. We hypothesize that during the northerly wind the bioaerosols were mostly comprised of Basidiospores, which is consistent with SEM images obtained during the measurement period. FröhlichNowoisky et al. (2012) reported that a region with dominant
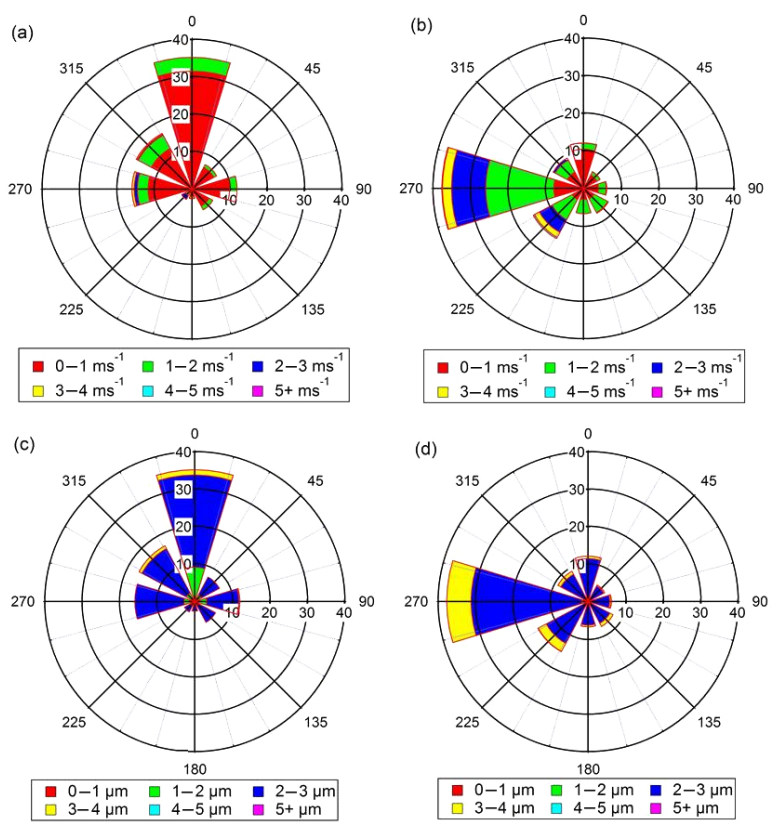

Figure 14. Wind rose diagram scaled by wind speed and the geometric mean diameter $\left(D_{\mathrm{g}}\right)$ of $\mathrm{d} N_{\mathrm{F}} / \operatorname{d} \log D_{\mathrm{a}}$. The figures have been separated for the FBAP number concentration $\left(N_{\mathrm{F}}\right)$ range, $N_{\mathrm{F}}>0.1$ and $N_{\mathrm{F}}<0.1 \mathrm{~cm}^{-3}$ observed during the high bio period. For example, when $N_{\mathrm{F}}>0.1 \mathrm{~cm}^{-3} \sim 60 \%$ of the time wind was observed to be in the range of $0-1 \mathrm{~ms}^{-1}$ (a) and $\sim 94 \%$ of the time, the geometric mean diameter $\left(D_{\mathrm{g}}\right)$ of $\mathrm{d} N_{\mathrm{F}} / \mathrm{d} \log D_{\mathrm{a}}$ was in the range of 2-3 $\mu \mathrm{m}$ (c). On the other hand, for $N_{\mathrm{F}}<0.1 \mathrm{~cm}^{-3} \sim 60 \%$ of the time, wind speed was greater than $1 \mathrm{~m} \mathrm{~s}^{-1}$ (b), and $\sim 80 \%$ of the time the geometric mean diameter $\left(D_{\mathrm{g}}\right)$ of $\mathrm{d} N_{\mathrm{F}} / \mathrm{d} \log D_{\mathrm{a}}$ was in the range of $2-3 \mu \mathrm{m}(\mathbf{d})$.

prevalence of marine air masses has larger proportions of Ascospores and, in contrast, the continental air masses exhibit higher proportions of Basidiospores. However, due to technical difficulties associated with sampling, we could not establish the identity of the spores observed at this observational site during westerly/southwesterly winds, and these details will be addressed in follow-up studies. The corresponding wind rose scaled by $D_{\mathrm{g}, \mathrm{T}}$ obtained from $\mathrm{d} N_{\mathrm{T}} / \mathrm{d} \log D_{\mathrm{a}}$ is shown in Fig. S23.

As shown in Table 5, the wind speed was observed to correlate negatively with $N_{\mathrm{F}}$ during the entire measurement period, and is consistent with previously reported studies (Hameed et al., 2012; Almaguer et al., 2013; Lyon et al., 1984; Quintero et al., 2010). The increased $N_{F}$ concentration levels during lower wind speed might indicate that observed bioaerosols were dominated by the local source rather than transported from longer distances (Sadys et al., 2014; Hara and Zhang, 2012; Bovallius et al., 1978; Maki et al., 2013; Prospero et al., 2005; Creamean et al., 2013), as lower wind speed may actually increase emission of some specific type of spores (Huffman et al., 2012; Jones and Harrison, 2004; Troutt and Levetin, 2001; Kurkela, 1997). 
Table 5. $R^{2}$ values for the correlation between meteorological parameters (RH, temperature and wind speed) and $N_{\mathrm{T}}, N_{\mathrm{F}}$ and $N_{\mathrm{F}} / N_{\mathrm{T}}$ during the entire campaign and each focus period.

\begin{tabular}{lrrr|rrr|rrr|rrr}
\hline & \multicolumn{3}{c}{ Campaign } & \multicolumn{3}{c|}{ Dusty } & \multicolumn{3}{c}{ Clean } & \multicolumn{3}{c}{ High bio } \\
& $N_{\mathrm{T}}$ & $N_{\mathrm{F}}$ & $N_{\mathrm{F}} / N_{\mathrm{T}}$ & $N_{\mathrm{T}}$ & $N_{\mathrm{F}}$ & $N_{\mathrm{F}} / N_{\mathrm{T}}$ & $N_{\mathrm{T}}$ & $N_{\mathrm{F}}$ & $N_{\mathrm{F}} / N_{\mathrm{T}}$ & $N_{\mathrm{T}}$ & $N_{\mathrm{F}}$ & $N_{\mathrm{F}} / N_{\mathrm{T}}$ \\
\hline RH & -0.64 & 0.58 & 0.85 & -0.25 & & 0.18 & -0.66 & -0.01 & 0.13 & -0.64 & 0.5 & 0.68 \\
Temperature & 0.45 & -0.65 & -0.82 & 0.34 & -0.04 & -0.25 & 0.78 & 0.02 & -0.2 & 0.43 & -0.68 & -0.83 \\
Wind speed & 0.4 & -0.6 & -0.78 & 0.09 & -0.18 & -0.31 & -0.18 & -0.27 & 0 & 0.3 & -0.61 & -0.74 \\
\hline
\end{tabular}
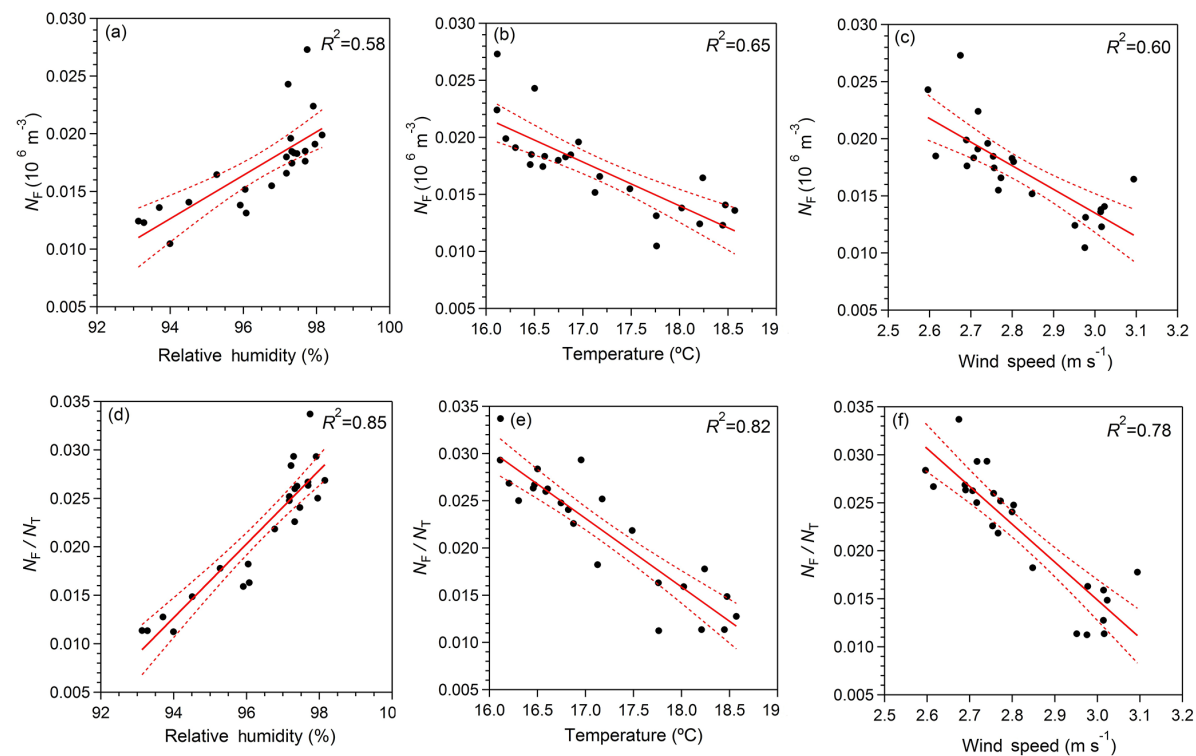

Figure 15. Correlation between aerosol particle number concentrations $\left(N_{\mathrm{F}}, N_{\mathrm{T}}\right.$, and $\left.N_{\mathrm{F}} / N_{\mathrm{T}}\right)$ and meteorological parameters (relative humidity, temperature, and wind speed). The red line indicates the best fit to the scattered points and the dashed black line indicates the $95 \%$ confidence level obtained for the best fit.

\subsubsection{Correlation with relative humidity and temperature}

The correlation coefficient derived between $N_{\mathrm{F}}$ and relative humidity averaged over the entire campaign is shown in Fig. 15, and corresponding $R^{2}$ values for three distinct focus periods are shown in Table 5. In general, an increase in $N_{\mathrm{F}}$ concentration with increasing relative humidity was observed with a moderate correlation coefficient $\left(R^{2}=0.58\right)$. Depending upon the type of bioaerosols, geographical location, and local climate, $N_{\mathrm{F}}$ has shown varied dependence on relative humidity and the precise response of the spore concentration to relative humidity is difficult to characterize. For example, a number of studies have shown that spores of genus like Cladosporium, Alternaria, and Epiccocum are known to exhibit the negative correlation with relative humidity (Oliveira et al., 2010; Herrero et al., 1996; Kurkela, 1997; Oh et al., 1998; Healy et al., 2014), while on the other hand, other studies have also found these spores to be positively correlated with relative humidity (Quintero et al., 2010; Hjelmroos, 1993; Ho et al., 2005). Genus like Ustilago and some other Basidiospores may exhibit a strong positive correlation with relative humidity (Sabariego et al., 2000; Quintero et al., 2010; Ho et al., 2005; Calderon et al., 1995). Ascospores concentrations are known to increase during and after rainfall (Burch and Levetin, 2002; Elbert et al., 2007; Hasnain, 1993; Hirst, 1953; Toutt and Levetin, 2001; Lyon et al., 1984; Oh et al., 1998), whereas Basidiospores exhibited a strong resemblance to the diurnal pattern of relative humidity (Li and Kendrick, 1994; Hasnain, 1993; Tarlo et al., 1979; Trout and Levetin, 2001). Almaguer et al. (2013) have reported that in a tropical region, relative humidity has greater influence than temperature on the airborne spore counts and may be a prerequisite for release of spores (Hollins et al., 2004). Thus, the combination of persistent threshold relative humidity $(\sim 60$ $95 \%$ as reported by Ho et al., 2005) and rainfall can cause the increase in the spore concentration and the excessive and persistent rain, however, tends to wash the spore out of the atmosphere further reducing their concentration levels (Burge, 1986; Horner et al., 1992; Troutt and Levetin, 2001). Based on these arguments combined with observed meteorological conditions we expect that the bioaerosols reported here 
from Munnar mainly consisted of Basidiospores during the SW monsoon season as also evident from SEM images (discussed above). This is consistent with results reported by Valsan et al. (2015) where they found the dominant presence of dry air spora (Cladosporium) during relatively dry and warm weather from the same observational site. In general, $N_{\mathrm{F}}$ and $N_{\mathrm{F}} / N_{\mathrm{T}}$ decreased with increasing wind speed $\left(R^{2}=0.6\right.$ and $R^{2}=0.78$, respectively) indicating that wind speed may be one of the strong factors for observed high $N_{\mathrm{F}}$ concentrations at this site. As compared to previously reported correlation between $N_{\mathrm{F}}$ and meteorological parameters (Santarpia et al., 2013), the relations shown for this observational site appeared to be more robust and conclusive. The variability observed in $N_{\mathrm{T}}\left(N_{\mathrm{T}}-N_{\mathrm{T}, \min } / N_{\mathrm{T}, \max }-N_{\mathrm{T}, \min }\right.$; not shown here) was more consistent and high as compared to variability observed in $N_{\mathrm{F}}\left(N_{\mathrm{F}}-N_{\mathrm{F}, \min } / N_{\mathrm{F}, \max }-N_{\mathrm{F}, \min }\right)$, which was more episodic and hence one would expect the weak correlation between $N_{\mathrm{T}}$ and meteorological parameters (Table 5).

Several studies have reported that in temperate regions, temperature is probably the most important meteorological parameter affecting the spore concentration (Levetin and Horner, 2002; Adhikari et al., 2006) with highest spore concentration during summer season (Emberlin et al., 1995; Hasnain, 1993; Herrero et al., 1996; Hjelmroos, 1993; Li et al., 2011; Schumacher et al., 2013). When the relation between temperature and spore concentration was investigated on the basis of diurnal average, spore concentration have been observed to decrease with the increasing temperature (Burch and Levetin, 2002; Calderon et al., 1995; Sabariego et al., 2000; Schumacher et al., 2013; Trejo et al., 2013). Consistent with this trend, we have found significant negative correlation between $N_{\mathrm{F}}$ and temperature $\left(R^{2}=0.65\right)$ averaged over the entire measurement period at Munnar. The correlation coefficient between $N_{\mathrm{F}}$ and temperature for three distinct focus periods is given in Table 5 and are specific to this locality of sampling and may not be extrapolated to represent behavior in other ecosystems in the Indian region. These results were, however, presented to formulate preliminary hypothesis about role of meteorological parameters in governing the variability of bioaerosols specific to this observational site for the monsoon season.

\section{Summary and conclusions}

A UV-APS was continuously operated during the SW monsoon season (1 June-21 August 2014) at Munnar in the Western Ghats in southern tropical India. The number and mass size distributions and corresponding concentrations of biological aerosol were quantified for three distinct focus periods, namely, dusty, high bio, and clean, identified based on the prominent wind direction. Over the course of the entire measurement period the coarse particle number concentration of FBAPs varied in the range of $0.2 \times 10^{-3}$ to $0.63 \mathrm{~cm}^{-3}$ with an arithmetic mean value of $0.02 \mathrm{~cm}^{-3}\left( \pm 0.02 \mathrm{~cm}^{-3}\right)$.
This average concentration accounted for $0.04-53 \%$ (mean value $2.1 \% \pm 4.05 \%$ ) of the total coarse particle number concentration. The coarse particle mass concentrations of FBAPs varied in the range of $0.5 \times 10^{-3}-4.93 \mu \mathrm{g} \mathrm{m}^{-3}$ with an arithmetic mean ( \pm standard deviation) value of 0.24 $( \pm 0.28) \mu \mathrm{g} \mathrm{m}^{-3}$.

The FBAP concentrations observed at Munnar during the southwest monsoon season were within the range but slightly on the lower side of the concentrations reported by previous researchers using various online and offline techniques from varying environments (Després et al., 2007; Huffman et al., 2010, 2012; Adhikari et al., 2004; Bovallius et al., 1978; Bowers, et al., 2009, 2013; Lee et al., 2010; MatthiasMaser and Jaenicke, 1995; Matthias-Maser et al., 2000; Shaffer and Lighthart, 1997; Tong and Lighthart, 1999; Wang et al., 2007; Li et al., 2011; Hameed et al., 2009; Bauer et al., 2008; Schumacher et al., 2013; Gabey et al., 2010, 2011, 2013; Saari et al., 2015; Toprak and Schnaiter, 2013; Healy et al., 2014). For brevity, here we compare the number concentrations observed at Munnar only with number concentrations from varying environments carried out using online measurements. Huffman et al. (2010) have reported coarsemode average FBAP number concentrations from 4 months of measurement to be $0.03 \mathrm{~cm}^{-3}$, which constituted $\sim 4 \%$ of total coarse-mode particles from the semi-urban site of Mainz in central Europe. The median FBAP concentration during the wet season of a pristine tropical Amazonian rainforest region was found to be $0.07 \mathrm{~cm}^{-3}$, which constituted $\sim 24 \%$ of the total coarse-mode particle number concentration (Huffman et al., 2012). By analyzing the full 1-year observations from a boreal forest in Hyytiala and a pine forest in Colorado, Schumacher et al. (2013) reported the highest FBAP concentrations in summer of $0.046 \mathrm{~cm}^{-3}$ (constituting $\sim 13 \%$ of the total coarse-mode particles) and $0.03 \mathrm{~cm}^{-3}$ (constituting $\sim 8.8 \%$ of the total coarse-mode particles), respectively. Healy et al. (2014) reported the average FBAP concentration of $\sim 0.01 \mathrm{~cm}^{-3}$ using the UV-APS measurements carried out within Killarney national park, Kerry, situated in the southwest of Ireland. Gabey et al. (2013), by performing the measurements at a high-altitude site in central France, reported averaged FBAP concentrations of 0.012 and $0.095 \mathrm{~cm}^{-3}$ using a two-wavelength $(280$ and $370 \mathrm{~nm}$, respectively) single-particle UV-induced fluorescence spectrometer. Gabey et al. (2010), from a tropical rainforest in Borneo, Malaysia, reported that a mean FBAP number fraction in the size range of $0.8-20 \mu \mathrm{m}$ was $\sim 55$ and $\sim 28 \%$ below and above the forest canopy, respectively. It is important to note, however, that the measurement results compared here were obtained from different instrumentations operating with different wavelengths.

The average observed $\mathrm{d} N_{\mathrm{F}} / \mathrm{d} \log D_{\mathrm{a}}$ exhibited a peak at $\sim 3 \mu \mathrm{m}$, which was consistent even during distinct focus periods with slight quantitative variation in the FBAP number concentration. Such a consistency in the peak of $\mathrm{d} N_{\mathrm{F}} / \mathrm{d} \log D_{\mathrm{a}}$ during the entire measurement period indicates 
that sources and types of bioaerosols did not exhibit considerable variability and diversity at Munnar during the southwest monsoon season. The peak observed in $\mathrm{d} N_{\mathrm{F}} / \mathrm{d} \log D_{\mathrm{a}}$ in this study is consistent with the range of the peaks published by previous researchers. At a semi-urban site in central Europe the peak in $\mathrm{d} N_{\mathrm{F}} / \mathrm{d} \log D_{\mathrm{a}}$ was observed at $\sim 3 \mu \mathrm{m}$ (Huffman et al., 2010). In the pristine tropical rainforest region of Amazonia a peak in $\mathrm{d} N_{\mathrm{F}} / \mathrm{d} \log D_{\mathrm{a}}$ was found at $\sim 2.5 \mu \mathrm{m}$ (Huffman et al., 2012), whereas the peak in $\mathrm{d} N_{\mathrm{F}} / \mathrm{d} \log D_{\mathrm{a}}$ at a boreal forest in Finland exhibited a strong seasonal dependence, with different modes at $\sim 1.5, \sim 3$, and $\sim 5 \mu$ m indicating differences in the bioaerosol sources (Schumacher et al., 2013). In the pine forest of Colorado the distinct peaks were observed at $\sim 1.5$ and $\sim 5 \mu \mathrm{m}$ (Schumacher et al., 2013). The mode at $\sim 3 \mu \mathrm{m}$ reported for Colorado is likely due to the fungal spore whose release mechanism is strongly governed by the combination of relative humidity and temperature (Huffman et al., 2010, and references therein).

On the diurnal scale a pronounced diurnal cycle with a $\sim 3 \mu$ m peak with a maximum concentration at $\sim 06: 00 \mathrm{~h}$ was observed when averaged over the entire measurement period. This general pattern is consistent with previous studies reporting the early morning peak in FBAP concentration for various environmental conditions (Healy et al., 2014; Huffman et al., 2012; Schumacher et al., 2013; Toprak and Schnaiter, 2013). The early morning peak was contributed by Basidiospores, as their release in the atmosphere is strongly coupled with relative humidity (Adhikari et al., 2006; Burch and Levetin, 2002; Hasnain, 1993; Healy et al., 2014; Ho et al., 2005; Huffman et al., 2012). This is also consistent with the SEM images shown and discussed above.

The meteorological parameters were observed to correlate significantly with FBAP concentration at Munnar. We observed that $N_{\mathrm{F}}$ followed a similar diurnal trend to that of relative humidity and was anti-correlated with temperature. As reported by previous studies from selected locations (Huffman et al., 2013; Schumacher et al., 2013; Prenni et al., 2013; Hirst 1953), we did not observe any sharp increase in $N_{\mathrm{F}}$ concentration immediately after or during rainfall. We hypothesize that the spore build-up and release of certain species can happen only at a certain threshold relative humidity (Jones and Harrison, 2004). Our results indicate that under the dry environmental conditions where relative humidity levels rarely attain such thresholds required, fungal spore release can cause the strong build-up of fungal spores inside fungal bodies. Under these conditions precipitation can cause the relative humidity levels to increase up to threshold required for fungal spore release in combination with mechanical splashing due to raindrops, and can cause the sudden and sharp increase in spore concentrations. By contrast, like in the present case, the persistent high-humidity conditions can cause the continuous release of the spore without an opportunity for build-up of fungal spores in the fungal body to be released during rainfall. It is also reported that persistent high levels of relative humidity can inhibit the sporulation
(Schumacher et al., 2013), further considerably reducing the spore release. More detailed measurements are required from the regions where relative humidity persistently remains low $(<60 \%)$ for an extended amount of time and experiences sudden rainfall. The correlation between $N_{\mathrm{F}}$ and wind speed was found to be strongly negative. Since the majority of the spore release was dominated by the local sources, the strong winds coming over from a westerly/southwesterly direction, which were relatively clean, might have caused the dilution of air mass, thus reducing the spore concentration.

Overall, the long-term measurements reported in this paper showed the quantitative and qualitative agreement with previously reported studies. The emissions and abundance of biological aerosol particles in Western Ghats air during the monsoon season appeared to be closely linked to the variability in the meteorological parameters. The scatter plot analysis carried out between $N_{\mathrm{F}}$ and $N_{\mathrm{T}}$ for sub-micron and supermicron particles indicated that sub-micron particles at this observational site were also dominated by aerosol particles of biological origin, thus indicating the lowest possible interference from particles of anthropogenic origin known to exhibit the fluorescence at the prescribed wavelength used in UV-APS. Hence, the given observational site can be termed relatively pristine while under the influence of the SW monsoon season. This emphasizes the need to perform similar measurements under different land-use types during the same season over the Indian region. The contrasting characteristics of this observational site associated with pollution and interference of non-biological aerosol particles in fluorescence will be discussed in follow-up studies. We propose more studies by means of performing simultaneous online measurements of biological aerosol particles under contrasting environments during distinct meteorological seasons over the Indian region. These measurements could be supplemented with advanced offline measurement techniques including SEM analysis, DNA analysis, and fluorescence microscopy of the samples collected in parallel with the measurements. We believe that such a comprehensive approach over the Indian region would be helpful in understanding the possible tight coupling between aerosol and hydrological cycles, especially during monsoon. This could also help to better understand the implication of biological aerosols for crops and human health where the agricultural industry has the major share in GDP to cater for the need of $18 \%$ of the world's total population.

\section{Data availability}

All data can be accessed using the given doi:10.6084/m9.figshare.3510288 (Valsan, 2016). The Supplement related to this article is available online
at doi:10.5194/acp-16-9805-2016-supplement. 
Acknowledgements. S. S. Gunthe acknowledges the combined financial support from the Max Planck Society and the Department of Science and Technology, Government of India, under the Max Planck Partner Group Program. The authors are thankful to M. Akila, P. Hema, S. Shika, S. Aliena, P. H. Hasitha, D. Reshma, K. A. Sanu, and Tabish U. Ansari for their support in the planning, execution, and completion of the measurement campaign. The authors thankfully acknowledge the support from Gerhard Lammel, Multiphase Chemistry Department, Max Planck Institute for Chemistry, for his support during the campaign and for providing the meteorological data for comparison. The authors are grateful to the Sophisticated Analytical Instrument Facility (SAIF), IIT Madras, for making SEM available for morphological analysis. The authors gratefully acknowledge the US Geological Survey for the topography data in DEM (digital elevation model) format and NOAA ARL for providing HYSPLIT air mass back-trajectory calculations. We are grateful to D. Baumgardner and two anonymous reviewers for their valuable comments, which has helped us to improve the overall quality of the paper.

Edited by: C. Hoyle

Reviewed by: D. Baumgardner and two anonymous referees

\section{References}

Adhikari, A., Sen, M. M., Gupta-Bhattacharya, S., and Chanda, S.: Air-borne viable, non-viable, and allergenic fungi in a rural agricultural area of India: a 2-year study at five outdoor sampling stations, Sci. Total Environ., 326, 123-141, doi:10.1016/j.scitotenv.2003.12.007, 2004.

Adhikari, A., Reponen, T., Grinshpun, S. A., Martuzevicius, D., and LeMasters, G.: Correlation of ambient inhalable bioaerosols with particulate matter and ozone: A two-year study, Environ. Pollut., 140, 16-28, doi:10.1016/j.envpol.2005.07.004, 2006.

Agranovski, V. and Ristovski, Z. D.: Real-time monitoring of viable bioaerosols: capability of the UVAPS to predict the amount of individual microorganisms in aerosol particles, J. Aerosol Sci., 36, 665-676, doi:10.1016/j.jaerosci.2004.12.005, 2005.

Agranovski, V., Ristovski, Z., Hargreaves, M., Blackall, P. J., and Morawska, L.: Performance evaluation of the UVAPS: influence of physiological age of airborne bacteria and bacterial stress, J. Aerosol Sci., 34, 1711-1727, doi:10.1016/s00218502(03)00191-5, 2003.

Agranovski, V., Ristovski, Z. D., Ayoko, G. A., and Morawska, L.: Performance evaluation of the UVAPS in measuring biological aerosols: Fluorescence spectra from NAD(P)H coenzymes and riboflavin, Aerosol Sci. Technol., 38, 354-364, doi:10.1080/02786820490437505, 2004.

Almaguer, M., Aira, M.-J., Rodríguez-Rajo, F. J., and Rojas, T. I.: Temporal dynamics of airborne fungi in Havana (Cuba) during dry and rainy seasons: influence of meteorological parameters, Int. J. Biometeorol., 58, 1459-1470, doi:10.1007/s00484-0130748-6, 2013.

Andreae, M. O. and Rosenfeld, D.: Aerosol-cloud-precipitation interactions. Part 1. The nature and sources of cloud-active aerosols, Earth Science Reviews, 89, 13-41, 2008.

Ansari, T. U., Valsan, A. E., Ojha, N., Ravikrishna, R., Narasimhan, B., and Gunthe, S. S.: Model simulations of fungal spore distri- bution over the Indian region, Atmos. Environ., 122, 552-560, doi:10.1016/j.atmosenv.2015.10.020, 2015.

Artaxo, P. and Hansson, H. C.: Size distribution of biogenic aerosolparticles from the Amazon basin, Atmos. Environ., 29, 393-402, doi:10.1016/1352-2310(94)00178-n, 1995.

Baron, P. A. and Willeke, K.: Aerosol Measurement - Principles, Techniques and Applications, 2nd edition, John Wiley \& Sons, ISBN-10: 0471784923, ISBN-13: 9780471784920, 2005.

Bauer, H., Schueller, E., Weinke, G., Berger, A., Hitzenberger, R., Marr, I. L., and Puxbaum, H.: Significant contributions of fungal spores to the organic carbon and to the aerosol mass balance of the urban atmospheric aerosol, Atmos. Environ., 42, 5542-5549, doi:10.1016/j.atmosenv.2008.03.019, 2008.

Bhati, H. S. and Gaur, R. D.: Studies on Aerobiology Atmospheric fungal spores, New Phytologist, 82, 519-527, doi:10.1111/j.1469-8137.1979.tb02678.x, 1979.

Bovallius, A., Bucht, B., Roffey, R., and Anas, P.: 3-Year investigation of natural airborne bacterial-flora at 4 localities in Sweden, Appl. Environ. Microb., 35, 847-852, 1978.

Bowers, R. M., Lauber, C. L., Wiedinmyer, C., Hamady, M., Hallar, A. G., Fall, R., Knight, R., and Fierer, N.: Characterization of Airborne Microbial Communities at a High-Elevation Site and Their Potential To Act as Atmospheric Ice Nuclei, Appl. Environ. Microb., 75, 5121-5130, doi:10.1128/aem.00447-09, 2009.

Bowers, R. M., Clements, N., Emerson, J. B., Wiedinmyer, C., Hannigan, M. P., and Fierer, N.: Seasonal Variability in Bacterial and Fungal Diversity of the Near-Surface Atmosphere, Environ. Sci. Technol., 47, 12097-12106, doi:10.1021/es402970s, 2013.

Brosseau, L. M., Vesley, D., Rice, N., Goodell, K., Nellis, M., and Hairston, P.: Differences in detected fluorescence among several bacterial species measured with a direct-reading particle sizer and fluorescence detector, Aerosol Sci. Technol., 32, 545-558, doi:10.1080/027868200303461, 2000.

Burch, M. and Levetin, E.: Effects of meteorological conditions on spore plumes, Int. J. Biometeorol., 46, 107-117, doi:10.1007/s00484-002-0127-1, 2002.

Burge, H. A.: Some comments on the aerobiology of fungus spores, Grana, 25, 143-146, 1986.

Burge, H. A. and Rogers, C. A.: Outdoor allergens, Environ. Health Persp., 108, 653-659, doi:10.2307/3454401, 2000.

Burrows, S. M., Butler, T., Jöckel, P., Tost, H., Kerkweg, A., Pöschl, U., and Lawrence, M. G.: Bacteria in the global atmosphere - Part 2: Modeling of emissions and transport between different ecosystems, Atmos. Chem. Phys., 9, 9281-9297, doi:10.5194/acp-9-9281-2009, 2009.

Calderon, C., Lacey, J., McCartney, H. A., and Rosas, I.: Seasonal and diurnal-variation of airborne basidiomycete spore concentrations in Mexico-city, Grana, 34, 260-268, 1995.

Chakraborty, P., Gupta-Bhattacharya, S., Chakraborty, C., Lacey, J., and Chanda, S.: Airborne allergenic pollen grains on a farm in West Bengal, India, Grana, 37, 53-57, 1998.

Coz, E., Artinano, B., Clark, L. M., Hernandez, M., Robinson, A. L., Casuccio, G. S., Lersch, T. L., and Pandis, S. N.: Characterization of fine primary biogenic organic aerosol in an urban area in the northeastern United States, Atmos. Environ., 44, 39523962, doi:10.1016/j.atmosenv.2010.07.007, 2010.

Crawford, I., Robinson, N. H., Flynn, M. J., Foot, V. E., Gallagher, M. W., Huffman, J. A., Stanley, W. R., and Kaye, P. H.: Characterisation of bioaerosol emissions from a Colorado pine for- 
est: results from the BEACHON-RoMBAS experiment, Atmos. Chem. Phys., 14, 8559-8578, doi:10.5194/acp-14-8559-2014, 2014.

Creamean, J. M., Suski, K. J., Rosenfeld, D., Cazorla, A., DeMott, P. J., Sullivan, R. C., White, A. B., Ralph, F. M., Minnis, P., Comstock, J. M., Tomlinson, J. M., and Prather, K. A.: Dust and Biological Aerosols from the Sahara and Asia Influence Precipitation in the Western U.S., Science, 339, 1572-1578, doi:10.1126/science.1227279, 2013.

DeCarlo, P. F., Slowik, J. G., Worsnop, D. R., Davidovits, P., and Jimenez, J. L.: Particle morphology and density characterization by combined mobility and aerodynamic diameter measurements. Part 1: Theory, Aerosol Sci. Technol., 38, 1185-1205, 2004.

DeLeon-Rodriguez, N., Lathem, T. L., Rodriguez-R, L. M., Barazesh, J. M., Anderson, B. E., Beyersdorf, A. J., Ziemba, L. D., Bergin, M., Nenes, A., and Konstantinidis, K. T.: Microbiome of the upper troposphere: Species composition and prevalence, effects of tropical storms, and atmospheric implications, P. Natl. Acad. Sci. USA, 110, 2575-2580, doi:10.1073/pnas.1212089110, 2013.

Després, V. R., Nowoisky, J. F., Klose, M., Conrad, R., Andreae, M. O., and Pöschl, U.: Characterization of primary biogenic aerosol particles in urban, rural, and high-alpine air by DNA sequence and restriction fragment analysis of ribosomal RNA genes, Biogeosciences, 4, 1127-1141, doi:10.5194/bg-4-1127-2007, 2007.

Després, V. R., Huffman, J. A., Burrows, S. M., Hoose, C., Safatov, A. S., Buryak, G., Frohlich-Nowoisky, J., Elbert, W., Andreae, M. O., Pöschl, U., and Jaenicke, R.: Primary biological aerosol particles in the atmosphere: a review, Tellus B, 64, 15598, doi:10.3402/tellusb.v64i0.15598, 2012.

Du, C., Liu, S., Yu, X., Li, X., Chen, C., Peng, Y., Dong, Y., Dong, Z., and Wang, F.: Urban Boundary Layer Height Characteristics and Relationship with Particulate Matter Mass Concentrations in Xi'an, Central China, Aerosol Air Qual. Res., 13, 1598-1607, doi:10.4209/aaqr.2012.10.0274, 2013.

Elbert, W., Taylor, P. E., Andreae, M. O., and Pöschl, U.: Contribution of fungi to primary biogenic aerosols in the atmosphere: wet and dry discharged spores, carbohydrates, and inorganic ions, Atmos. Chem. Phys., 7, 4569-4588, doi:10.5194/acp-7-4569-2007, 2007.

Emberlin, J., Newman, T., and Bryant, R.: The incidence of fungal spores in the ambient air and inside homes: Evidence from London, Aerobiologia, 11, 253-258, doi:10.1007/bf02447205, 1995.

Fisher, M. C., Henk, D. A., Briggs, C. J., Brownstein, J. S., Madoff, L. C., McCraw, S. L., and Gurr, S. J.: Emerging fungal threats to animal, plant and ecosystem health, Nature, 484, 186-194, doi:10.1038/nature10947, 2012.

Fröhlich-Nowoisky, J., Pickersgill, D. A., Desprès, V. R., and Pöschl, U.: High diversity of fungi in air particulate matter, P. Natl. Acad. Sci. USA, 106, 12814-12819, doi:10.1073/pnas.0811003106, 2009.

Fröhlich-Nowoisky, J., Burrows, S. M., Xie, Z., Engling, G., Solomon, P. A., Fraser, M. P., Mayol-Bracero, O. L., Artaxo, P., Begerow, D., Conrad, R., Andreae, M. O., Després, V. R., and Pöschl, U.: Biogeography in the air: fungal diversity over land and oceans, Biogeosciences, 9, 1125-1136, doi:10.5194/bg9-1125-2012, 2012.

Fuzzi, S., Mandrioli, P., and Perfetto, A.: Fog droplets - An atmospheric source of secondary biological aerosol particles, At- mos. Environ., 31, 287-290, doi:10.1016/1352-2310(96)001604, 1997.

Gabey, A. M., Gallagher, M. W., Whitehead, J., Dorsey, J. R., Kaye, P. H., and Stanley, W. R.: Measurements and comparison of primary biological aerosol above and below a tropical forest canopy using a dual channel fluorescence spectrometer, Atmos. Chem. Phys., 10, 4453-4466, doi:10.5194/acp-10-4453-2010, 2010.

Gabey, A. M., Stanley, W. R., Gallagher, M. W., and Kaye, P. H.: The fluorescence properties of aerosol larger than $0.8 \mu \mathrm{m}$ in urban and tropical rainforest locations, Atmos. Chem. Phys., 11, 5491-5504, doi:10.5194/acp-11-5491-2011, 2011.

Gabey, A. M., Vaitilingom, M., Freney, E., Boulon, J., Sellegri, K., Gallagher, M. W., Crawford, I. P., Robinson, N. H., Stanley, W. R., and Kaye, P. H.: Observations of fluorescent and biological aerosol at a high-altitude site in central France, Atmos. Chem. Phys., 13, 7415-7428, doi:10.5194/acp-13-7415-2013, 2013.

Gangamma, S.: Characteristics of airborne bacteria in Mumbai urban environment, Sci. Total Environ., 488, 70-74, doi:10.1016/j.scitotenv2014.04.065, 2014.

Garland, R. M., Schmid, O., Nowak, A., Achtert, P., Wiedensohler, A., Gunthe, S. S., Takegawa, N., Kita, K., Kondo, Y., Hu, M., Shao, M., Zeng, L. M., Zhu, T., Andreae, M. O., and Pöschl, U.: Aerosol optical properties observed during Campaign of Air Quality Research in Beijing 2006 (CAREBeijing2006): Characteristic differences between the inflow and outflow of Beijing city air, J. Geophys. Res.-Atmos., 114, D00G04, doi:10.1029/2008JD010780, 2009.

Grand, L. F. and Vandyke, C. G.: Scanning electron microscopy of basidiospores of species of hydnellum, hydnum, phellodon, and bankera (hydnaceae), J. Elisha Mitch. Sci. S., 92, 114-123, 1976.

Hairston, P. P., Ho, J., and Quant, F. R.: Design of an instrument for real-time detection of bioaerosols using simultaneous measurement of particle aerodynamic size and intrinsic fluorescence, J. Aerosol Sci., 28, 471-482, doi:10.1016/s0021-8502(96)00448-x, 1997.

Hallar, A. G., Chirokova, G., McCubbin, I., Painter, T. H., Wiedinmyer, C., and Dodson, C.: Atmospheric bioaerosols transported via dust storms in the western United States, Geophys. Res. Lett., 38, L17801, doi:10.1029/2011g1048166, 2011.

Hameed, A. A. A., Khoder, M. I., Yuosra, S., Osman, A. M., and Ghanem, S.: Diurnal distribution of airborne bacteria and fungi in the atmosphere of Helwan area, Egypt, Sci. Total Environ., 407, 6217-6222, doi:10.1016/j.scitotenv.2009.08.028, 2009.

Hameed, A. A. A., Khoder, M. I., Ibrahim, Y. H., Saeed, Y., Osman, M. E., and Ghanem, S.: Study on some factors affecting survivability of airborne fungi, Sci. Total Environ., 414, 696-700, doi:10.1016/j.scitotenv.2011.10.042, 2012.

Hara, K. and Zhang, D.: Bacterial abundance and viability in long-range transported dust, Atmos. Environ., 47, 20-25, doi:10.1016/j.atmosenv.2011.11.050, 2012.

Hasnain, S. M.: Influence of meteorological factors on the air spora, Grana, 32, 184-188, 1993.

Healy, D. A., Huffman, J. A., O'Connor, D. J., Pöhlker, C., Pöschl, U., and Sodeau, J. R.: Ambient measurements of biological aerosol particles near Killarney, Ireland: a comparison between real-time fluorescence and microscopy techniques, Atmos. Chem. Phys., 14, 8055-8069, doi:10.5194/acp-14-8055$2014,2014$. 
Herrero, B., Fombella-Blanco, M. A., Fernandez-Gonzalez, D., and Valencia-Barrera, R. M.: The role of meteorological factors in determining the annual variation of Alternaria and Cladosporium snores in the atmosphere of Palencia, 1990-1992, Int. J. Biometeorol., 39, 139-142, doi:10.1007/bf01211226, 1996.

Hirst, J. M.: Changes in atmospheric spore content: Diurnal periodicity and the effects of weather, T. Brit. Mycol. Soc., 36, 375IN378, doi:10.1016/S0007-1536(53)80034-3, 1953.

Hjelmroos, M.: Relationship between airborne fungal spore presence and weather variables - cladosporium and alternaria, Grana, 32, 40-47, 1993.

Ho, H. M., Rao, C. Y., Hsu, H. H., Chiu, Y. H., Liu, C. M., and Chao, H. J.: Characteristics and determinants of ambient fungal spores in Hualien, Taiwan, Atmos. Environ., 39, 5839-5850, doi:10.1016/j.atmonsenv.2005.06.034, 2005.

Hollins, P. D., Kettlewell, P. S., Atkinson, M. D., Stephenson, D. B., Corden, J. M., Millington, W. M., and Mullins, J.: Relationships between airborne fungal spore concentration of Cladosporium and the summer climate at two sites in Britain, Int. J. Biometeorol., 48, 137-141, doi:10.1007/s00484-003-0188-9, 2004.

Horner, W. E., Oneil, C. E., and Lehrer, S. B.: Basidiospore aeroallergens, Clin. Rev. Allerg., 10, 191-211, 1992.

Huffman, J. A., Treutlein, B., and Pöschl, U.: Fluorescent biological aerosol particle concentrations and size distributions measured with an Ultraviolet Aerodynamic Particle Sizer (UVAPS) in Central Europe, Atmos. Chem. Phys., 10, 3215-3233, doi:10.5194/acp-10-3215-2010, 2010.

Huffman, J. A., Sinha, B., Garland, R. M., Snee-Pollmann, A., Gunthe, S. S., Artaxo, P., Martin, S. T., Andreae, M. O., and Pöschl, U.: Size distributions and temporal variations of biological aerosol particles in the Amazon rainforest characterized by microscopy and real-time UV-APS fluorescence techniques during AMAZE-08, Atmos. Chem. Phys., 12, 11997-12019, doi:10.5194/acp-12-11997-2012, 2012.

Huffman, J. A., Prenni, A. J., DeMott, P. J., Pöhlker, C., Mason, R. H., Robinson, N. H., Fröhlich-Nowoisky, J., Tobo, Y., Després, V. R., Garcia, E., Gochis, D. J., Harris, E., Müller-Germann, I., Ruzene, C., Schmer, B., Sinha, B., Day, D. A., Andreae, M. O., Jimenez, J. L., Gallagher, M., Kreidenweis, S. M., Bertram, A. K., and Pöschl, U.: High concentrations of biological aerosol particles and ice nuclei during and after rain, Atmos. Chem. Phys., 13, 6151-6164, doi:10.5194/acp-13-6151-2013, 2013.

Jones, A. M. and Harrison, R. M.: The effects of meteorological factors on atmospheric bioaerosol concentrations - a review, Sci. Total Environ., 326, 151-180, doi:10.1016/j.scitotenv.2003.11.021, 2004.

Kanaani, H., Hargreaves, M., Ristovski, Z., and Morawska, L.: Performance assessment of UVAPS: Influence of fungal spore age and air exposure, J. Aerosol Sci., 38, 83-96, doi:10.1016/j.jaerosci.2006.10.003, 2007.

Kanaani, H., Hargreaves, M., Smith, J., Ristovski, Z., Agranovski, V., and Morawska, L.: Performance of UVAPS with respect to detection of airborne fungi, J. Aerosol Sci., 39, 175-189, doi:10.1016/j.jaerosci.2007.10.007, 2008.

Kanawade, V. P., Shika, S., Poehlker, C., Rose, D., Suman, M. N. S., Gadhavi, H., Kumar, A., Nagendra, S. M. S., Ravikrishna, R., Yu, H., Sahu, L. K., Jayaraman, A., Andreae, M. O., Poeschl, U., and Gunthe, S. S.: Infrequent occurrence of new particle formation at a semi-rural location, Gadanki, in tropical Southern India, Atmos. Environ., 94, 264-273, doi:10.1016/j.atmosenv.2014.05.046, 2014.

Kurkela, T.: The number of Cladosporium conidia in the air in different weather conditions, Grana, 36, 54-61, 1997.

Lee, S.-H., Lee, H.-J., Kim, S.-J., Lee, H. M., Kang, H., and Kim, Y. P.: Identification of airborne bacterial and fungal community structures in an urban area by T-RFLP analysis and quantitative real-time PCR, Sci. Total Environ., 408, 1349-1357, doi:10.1016/j.scitotenv.2009.10.061, 2010.

Levetin, E. and Horner, W. E.: Fungal aerobiology: Exposure and measurement, Chem. Immunol., 81, 10-27, 2002.

Li, D. W. and Kendrick, B.: Functional-relationships between airborne fungal spores and environmental-factors in KitchenerWaterloo, Ontario, as detected by canonical correspondenceanalysis, Grana, 33, 166-176, 1994.

Li, F. and Ramanathan, V.: Winter to summer monsoon variation of aerosol optical depth over the tropical Indian Ocean, J. Geophys. Res.-Atmos., 107, 4284, doi:10.1029/2001jd000949, 2002.

Li, M., Qi, J., Zhang, H., Huang, S., Li, L., and Gao, D.: Concentration and size distribution of bioaerosols in an outdoor environment in the Qingdao coastal region, Sci. Total Environ., 409, 3812-3819, doi:10.1016/j.scitotenv.2011.06.001, 2011.

Lyon, F. L., Kramer, C. L., and Eversmeyer, M. G.: Variation of airspora in the atmosphere due to weather conditions, Grana, 23, 177-181, 1984.

Madden, L. V.: Effects of rain on splash dispersal of fungal pathogens, Can. J. Plant Pathol., 19, 225-230, 1997.

Maki, T., Kakikawa, M., Kobayashi, F., Yamada, M., Matsuki, A., Hasegawa, H., and Iwasaka, Y.: Assessment of composition and origin of airborne bacteria in the free troposphere over Japan, Atmos. Environ., 74, 73-82, doi:10.1016/j.atmosenv.2013.03.029, 2013.

Matthias-Maser, S., Obolkin, V., Khodzer, T., and Jaenicke, R.: Seasonal variation of primary biological aerosol particles in the remote continental region of Lake Baikal/Siberia, Atmos. Environ., 34, 3805-3811, doi:10.1016/s1352-2310(00)00139-4, 2000.

Matthias-Maser, S. and Jaenicke, R.: A method to identify biological aerosol-particles with radius greater-than $0.3 \mu \mathrm{m}$ for the determination of their size distribution, J. Aerosol Sci., 22, S849S852, doi:10.1016/s0021-8502(05)80232-0, 1991.

Matthias-Maser, S. and Jaenicke, R.: Examination of atmospheric bioaerosol particles with radii greater-than- $0.2 \mu \mathrm{m}$, J. Aerosol Sci., 25, 1605-1613, doi:10.1016/0021-8502(94)90228-3, 1994.

Matthias-Maser, S. and Jaenicke, R.: The size distribution of primary biological aerosol particles with radii $>0.2 \mu \mathrm{m}$ in an urban rural influenced region, Atmos. Res., 39, 279-286, doi:10.1016/0169-8095(95)00017-8, 1995.

Möhler, O., DeMott, P. J., Vali, G., and Levin, Z.: Microbiology and atmospheric processes: the role of biological particles in cloud physics, Biogeosciences, 4, 1059-1071, doi:10.5194/bg-4-10592007, 2007.

Moorthy, K. K., Nair, P. R., and Murthy, B. V. K.: Size distribution of coastal aerosols - effects of local-sources and sinks, J. Appl. Meteorol., 30, 844-852, doi:10.1175/15200450(1991)030<0844:sdocae>2.0.co;2, 1991.

Morris, C. E., Georgakopoulos, D. G., and Sands, D. C.: Ice nucleation active bacteria and their potential role in precipitation, J. Phys. IV, 121, 87-103, doi:10.1051/jp4:2004121004, 2004. 
Morris, C. E., Conen, F., Huffman, J. A., Phillips, V., Poeschl, U., and Sands, D. C.: Bioprecipitation: a feedback cycle linking Earth history, ecosystem dynamics and land use through biological ice nucleators in the atmosphere, Glob. Change Biol., 20, 341-351, doi:10.1111/gcb.12447, 2014.

Myers, N., Mittermeier, R. A., Mittermeier, C. G., da Fonseca, G. A. B., and Kent, J.: Biodiversity hotspots for conservation priorities, Nature, 403, 853-858, doi:10.1038/35002501, 2000.

Naja, M. and Lal, S.: Surface ozone and precursor gases at Gadanki (13.5 degrees N, 79.2 degrees E), a tropical rural site in India, J. Geophys. Res.-Atmos., 107, 4197, doi:10.1029/2001jd000357, 2002.

Oh, J.-W., Lee, H.-B., Lee, H.-R., Pyun, B.-Y., Ahn, Y.-M., Kim, K.-E., Lee, S.-Y., and Lee, S.-I.: Aerobiological study of pollen and mold in Seoul, Korea, Allergology International, 47, 263270, doi:10.2332/allergolint.47.263, 1998.

Oliveira, M., Amorim, M. I., Ferreira, E., Delgado, L., and Abreu, I.: Main airborne Ascomycota spores: characterization by culture, spore morphology, ribosomal DNA sequences and enzymatic analysis, Appl. Microbiol. Biot., 86, 1171-1181, doi:10.1007/s00253-010-2448-z, 2010.

Pachauri, T., Singla, V., Satsangi, A., Lakhani, A., and Kumari, K. M.: Characterization of major pollution events (dust, haze, and two festival events) at Agra, India, Environ. Sci. Pollut. R., 20, 5737-5752, doi:10.1007/s11356-013-1584-2, 2013.

Pan, Y. L., Holler, S., Chang, R. K., Hill, S. C., Pinnick, R. G., Niles, S., and Bottiger, J. R.: Single-shot fluorescence spectra of individual micrometer-sized bioaerosols illuminated by a 351- or a 266-nm ultraviolet laser, Opt. Lett., 24, 116-118, doi:10.1364/ol.24.000116, 1999a.

Pan, Y. L., Holler, S., Chang, R. K., Hill, S. C., Pinnick, R. G., Niles, S., Bottiger, J. R., and Bronk, B. V.: Real-time detection and characterization of individual flowing airborne biological particles: fluorescence spectra and elastic scattering measurements, in: Air Monitoring and Detection of Chemical and Biological Agents Ii, edited by: Leonelli, J., and Althouse, M. L., Proceedings of the Society of Photo-Optical Instrumentation Engineers (Spie), 117 $125,1999 b$.

Pöhlker, C., Huffman, J. A., and Pöschl, U.: Autofluorescence of atmospheric bioaerosols - fluorescent biomolecules and potential interferences, Atmos. Meas. Tech., 5, 37-71, doi:10.5194/amt-537-2012, 2012.

Pöhlker, C., Huffman, J. A., Förster, J.-D., and Pöschl, U.: Autofluorescence of atmospheric bioaerosols: spectral fingerprints and taxonomic trends of pollen, Atmos. Meas. Tech., 6, 3369-3392, doi:10.5194/amt-6-3369-2013, 2013.

Pöschl, U.: Atmospheric aerosols: Composition, transformation, climate and health effects, Angew. Chem.-Int. Edit., 44, 75207540, doi:10.1002/anie.200501122, 2005.

Pöschl, U., Martin, S. T., Sinha, B., Chen, Q., Gunthe, S. S., Huffman, J. A., Borrmann, S., Farmer, D. K., Garland, R. M., Helas, G., Jimenez, J. L., King, S. M., Manzi, A., Mikhailov, E., Pauliquevis, T., Petters, M. D., Prenni, A. J., Roldin, P., Rose, D., Schneider, J., Su, H., Zorn, S. R., Artaxo, P., and Andreae, M. O.: Rainforest Aerosols as Biogenic Nuclei of Clouds and Precipitation in the Amazon, Science, 329, 15131516, doi:10.1126/science.1191056, 2010.

Pranesha, T. S. and Kamra, A. K.: Scavenging of aerosol particles by large water drops: 2 . The effect of electrical forces, J. Geo- phys. Res.-Atmos., 102, 23937-23946, doi:10.1029/97jd01834, 1997a.

Pranesha, T. S. and Kamra, A. K.: Scavenging of aerosol particles by large water drops: 3. Washout coefficients, half-lives, and rainfall depths, J. Geophys. Res.-Atmos., 102, 23947-23953, doi:10.1029/97jd01835, 1997b.

Prenni, A. J., Petters, M. D., Kreidenweis, S. M., Heald, C. L., Martin, S. T., Artaxo, P., Garland, R. M., Wollny, A. G., and Pöschl, U.: Relative roles of biogenic emissions and Saharan dust as ice nuclei in the Amazon basin, Nat. Geosci., 2, 401-404, 2009.

Prenni, A. J., Tobo, Y., Garcia, E., DeMott, P. J., Huffman, J. A., McCluskey, C. S., Kreidenweis, S. M., Prenni, J. E., Poehlker, C., and Poeschl, U.: The impact of rain on ice nuclei populations at a forested site in Colorado, Geophys. Res. Lett., 40, 227-231, doi:10.1029/2012g1053953, 2013.

Prospero, J. M.: Mineral and sea salt aerosol concentrations in various ocean regions, J. Geophys. Res.-Oceans, 84, 725-731, doi:10.1029/JC084iC02p00725, 1979.

Prospero, J. M., Blades, E., Mathison, G., and Naidu, R.: Interhemispheric transport of viable fungi and bacteria from Africa to the Caribbean with soil dust, Aerobiologia, 21, 1-19, doi:10.1007/s10453-004-5872-7, 2005.

Quintero, E., Rivera-Mariani, F., and Bolanos-Rosero, B.: Analysis of environmental factors and their effects on fungal spores in the atmosphere of a tropical urban area (San Juan, Puerto Rico), Aerobiologia, 26, 113-124, doi:10.1007/s10453-009-9148-0, 2010.

Raatikainen, T., Hyvarinen, A. P., Hatakka, J., Panwar, T. S., Hooda, R. K., Sharma, V. P., and Lihavainen, H.: The effect of boundary layer dynamics on aerosol properties at the Indo-Gangetic plains and at the foothills of the Himalayas, Atmos. Environ., 89, 548555, doi:10.1016/j.atmosenv.2014.02.058, 2014.

Radke, L. F., Hobbs, P. V., and Eltgroth, M. W.: Scavenging of aerosol-particles by precipitation, J. Appl. Meteorol., 19, 715722, doi:10.1175/1520-0450(1980)019<0715:soapbp>2.0.co;2, 1980.

Saari, S., Niemi, J. V., Ronkko, T., Kuuluvainen, H., Jarvinen, A., Pirjola, L., Aurela, M., Hillamo, R., and Keskinen, J.: Seasonal and Diurnal Variations of Fluorescent Bioaerosol Concentration and Size Distribution in the Urban Environment, Aerosol Air Qual. Res., 15, 572-581, doi:10.4209/aaqr.2014.10.0258, 2015.

Saari, S., Reponen, T., and Keskinen, J.: Performance of Two Fluorescence - Based Real-Time Bioaerosol Detectors: Bioscout vs. UVAPS, Aerosol Sci. Technol., 48, 371-378, doi:10.1080/02786826.2013.877579, 2014.

Sabariego, S., de la Guardia, C. D., and Alba, F.: The effect of meteorological factors on the daily variation of airborne fungal spores in Granada (southern Spain), Int. J. Biometeorol., 44, 1-5, doi:10.1007/s004840050131, 2000.

Sadys, M., Skjoth, C. A., and Kennedy, R.: Back-trajectories show export of airborne fungal spores (Ganoderma sp.) from forests to agricultural and urban areas in England, Atmos. Environ., 84, 88-99, doi:10.1016/j.atmosenv.2013.11.015, 2014.

Santarpia, J. L., Ratnesar-Shumate, S., Gilberry, J. U., and Quizon, J. J.: Relationship Between Biologically Fluorescent Aerosol and Local Meteorological Conditions, Aerosol Sci. Technol., 47, 655-661, doi:10.1080/02786826.2013.781263, 2013.

Satheesh, S. K. and Srinivasan, J.: Enhanced aerosol loading over Arabian Sea during the pre-monsoon season: Nat- 
ural or anthropogenic?, Geophys. Res. Lett., 29, 1874, doi:10.1029/2002g1015687, 2002.

Schumacher, C. J., Pöhlker, C., Aalto, P., Hiltunen, V., Petäjä, T., Kulmala, M., Pöschl, U., and Huffman, J. A.: Seasonal cycles of fluorescent biological aerosol particles in boreal and semiarid forests of Finland and Colorado, Atmos. Chem. Phys., 13, 11987-12001, doi:10.5194/acp-13-11987-2013, 2013.

Sesartic, A. and Dallafior, T. N.: Global fungal spore emissions, review and synthesis of literature data, Biogeosciences, 8, 11811192, doi:10.5194/bg-8-1181-2011, 2011.

Shaffer, B. T. and Lighthart, B.: Survey of culturable airborne bacteria at four diverse locations in Oregon: Urban, rural, forest, and coastal, Microb. Ecol., 34, 167-177, doi:10.1007/s002489900046, 1997.

Sharma, N. K., and Rai, A. K.: Allergenicity of airborne cyanobacteria Phormidium fragile and Nostoc muscorum, Ecotox. Environ. Safe., 69, 158-162, doi:10.1016/j.ecoenv.2006.08.006, 2008.

Sherman, J. P., Sheridan, P. J., Ogren, J. A., Andrews, E., Hageman, D., Schmeisser, L., Jefferson, A., and Sharma, S.: A multi-year study of lower tropospheric aerosol variability and systematic relationships from four North American regions, Atmos. Chem. Phys., 15, 12487-12517, doi:10.5194/acp-15-12487-2015, 2015.

Shika, S., Pholher, C., Rose, D., Suman, M. N. S, Gahavi, H., ShivaNagendra, S. M., Ravikrishna, R., Jayaraman, A., Andreae, M. O., Pöschl, U., and Gunthe, S. S. : Atmospheric aerosol properties at a semi-rural location in South India: particle size distributions and implications for cloud formation, to be submitted to Aerosols and Air Quality Research, 2016.

Sivaprakasam, V., Huston, A. L., Scotto, C., and Eversole, J. D.: Multiple UV wavelength excitation and fluorescence of bioaerosols, Opt. Express, 12, 4457-4466, doi:10.1364/opex.12.004457, 2004.

Spracklen, D. V. and Heald, C. L.: The contribution of fungal spores and bacteria to regional and global aerosol number and ice nucleation immersion freezing rates, Atmos. Chem. Phys., 14, 90519059, doi:10.5194/acp-14-9051-2014, 2014.

Srivastava, A., Singh, M., and Jain, V. K.: Identification and characterization of size-segregated bioaerosols at Jawaharlal Nehru University, New Delhi, Nat. Hazards, 60, 485-499, doi:10.1007/s11069-011-0022-3, 2012.

Tarlo, S. M., Bell, B., Srinivasan, J., Dolovich, J., and Hargreave, F. E.: Human sensitization to ganoderma antigen, J. Allergy Clin. Immun., 64, 43-49, doi:10.1016/0091-6749(79)90082-4, 1979.

Tong, Y. and Lighthart, B.: Diurnal Distribution of Total and Culturable Atmospheric Bacteria at a Rural Site, Aerosol Sci. Technol., 30, 246-254, doi:10.1080/027868299304822, 1999.
Toprak, E. and Schnaiter, M.: Fluorescent biological aerosol particles measured with the Waveband Integrated Bioaerosol Sensor WIBS-4: laboratory tests combined with a one year field study, Atmos. Chem. Phys., 13, 225-243, doi:10.5194/acp-13225-2013, 2013.

Trejo, M., Douarche, C., Bailleux, V., Poulard, C., Mariot, S., Regeard, C., and Raspaud, E.: Elasticity and wrinkled morphology of Bacillus subtilis pellicles, P. Natl. Acad. Sci. USA, 110, 2011-2016, doi:10.1073/pnas.1217178110, 2013.

Troutt, C. and Levetin, E.: Correlation of spring spore concentrations and meteorological conditions in Tulsa, Oklahoma, Int. J. Biometeorol., 45, 64-74, doi:10.1007/s004840100087, 2001.

Valsan, A.: FBAP monsoon measurement data, available at: doi:10.6084/m9.figshare.3510288, 2016.

Valsan, A. E., Priyamvada, H., Ravikrishna, R., Després, V. R., Biju, C. V., Sahu, L. K., Kumar, A., Verma, R. S., Philip, L., and Gunthe, S. S.: Morphological characteristics of bioaerosols from contrasting locations in southern tropical India - A case study, Atmos. Environ., 122, 321-331, doi:10.1016/j.atmosenv.2015.09.071, 2015.

Vinoj, V. and Satheesh, S. K.: Measurements of aerosol optical depth over Arabian Sea during summer monsoon season, Geophys. Res. Lett., 30, 1263, doi:10.1029/2002g1016664, 2003.

Vinoj, V., Satheesh, S. K., and Moorthy, K. K.: Optical, radiative, and source characteristics of aerosols at Minicoy, a remote island in the southern Arabian Sea, J. Geophys. Res.-Atmos., 115, D01201, doi:10.1029/2009jd011810, 2010.

Vinoj, V., Rasch, P. J., Wang, H., Yoon, J.-H., Ma, P.-L., Landu, K., and Singh, B.: Short-term modulation of Indian summer monsoon rainfall by West Asian dust, Nat. Geosci., 7, 308-313, doi:10.1038/ngeo2107, 2014.

Wang, C.-C., Fang, G.-C., and Lee, L.: Bioaerosols study in central Taiwan during summer season, Toxicol. Ind. Health, 23, 133139, doi:10.1177/0748233707078741, 2007.

Yu, X., Wang, Z., Zhang, M., Kuhn, U., Xie, Z., Cheng, Y., Pöschl, U., and Su, H.: Ambient measurement of fluorescent aerosol particles with a WIBS in the Yangtze River Delta of China: potential impacts of combustion-generated aerosol particles, Atmos. Chem. Phys. Discuss., doi:10.5194/acp-2016-228, in review, 2016.

Zhang, T., Engling, G., Chan, C.-Y., Zhang, Y.-N., Zhang, Z.-S., Lin, M., Sang, X.-F., Li, Y. D., and Li, Y.-S.: Contribution of fungal spores to particulate matter in a tropical rainforest, Environ. Res. Lett., 5, 024010, doi:10.1088/1748-9326/5/2/024010, 2010 . 